Article

\title{
Prognostic Significance of SATB1, SMAD3, Ezrin and $\beta$-Catenin in Patients with Pancreatic Adenocarcinoma
}

\author{
Justyna Durślewicz 1,*(D), Anna Klimaszewska-Wiśniewska 1(D), Ewa Domanowska ${ }^{1}$, \\ Natalia Skoczylas-Makowska ${ }^{1}$, Paulina Antosik ${ }^{1}$ (D), Wioletta Zielińska ${ }^{2}$ (D), Arkadiusz Gzil ${ }^{1}$ (D), \\ Paulina Czajkowska ${ }^{2}$, Klaudia Mikołajczyk ${ }^{2}$ and Dariusz Grzanka ${ }^{1}$ (D)
}

1 Department of Clinical Pathomorphology, Faculty of Medicine, Collegium Medicum in Bydgoszcz, Nicolaus Copernicus University in Torun, 85-094 Bydgoszcz, Poland; ania.klimaszewska@op.pl (A.K.-W.); ewdom@cm.umk.pl (E.D.); n.makowska@cm.umk.pl (N.S.-M.); paulina.antosik@cm.umk.pl (P.A.); arkadiuszgzilresearch@gmail.com (A.G.); d_grzanka@cm.umk.pl (D.G.)

2 Department of Histology and Embryology, Faculty of Medicine, Collegium Medicum in Bydgoszcz, Nicolaus Copernicus University in Torun, 85-092 Bydgoszcz, Poland; w.zielinska@cm.umk.pl (W.Z.); paulina.czajkowska25@gmail.com (P.C.); klaudia.mikolajczyk@cm.umk.pl (K.M.)

* Correspondence: justyna.durslewicz@cm.umk.pl; Tel.: +48-52-585-42-00

check for updates

Citation: Durślewicz, J.; Klimaszewska-Wiśniewska, A.; Domanowska, E.; SkoczylasMakowska, N.; Antosik, P.; Zielińska, W.; Gzil, A.; Czajkowska, P.; Mikołajczyk, K.; Grzanka, D. Prognostic Significance of SATB1, SMAD3, Ezrin and $\beta$-Catenin in Patients with Pancreatic

Adenocarcinoma. Appl. Sci. 2022, 12, 306. https://doi.org/10.3390/ app12010306

Academic Editor: Carmela Spagnuolo

Received: 9 November 2021 Accepted: 23 December 2021 Published: 29 December 2021

Publisher's Note: MDPI stays neutral with regard to jurisdictional claims in published maps and institutional affiliations.

Copyright: (C) 2021 by the authors. Licensee MDPI, Basel, Switzerland. This article is an open access article distributed under the terms and conditions of the Creative Commons Attribution (CC BY) license (https:// creativecommons.org/licenses/by/ $4.0 /)$.

\begin{abstract}
The present study aimed to explore the role of SATB1, SMAD3, Ezrin and $\beta$-catenin as individual and combined biomarkers for the survival prediction in pancreatic adenocarcinoma (PAC). Notably, this study distinguished for the first time a potential prognostic value of SATB1 corresponding to its subcellular localization in PAC. Immunohistochemical staining on tissue macroarrays, as well as RNA-seq data from public sources, were investigated, and the results correlated with overall survival (OS) and clinicopathological features. The connectivity between the examined factors, as well as their common signaling pathways, were demonstrated by the functional enrichment analysis. Herein, the prognostic ability of cytoplasmic SATB1 in OS analysis was even superior to nuclear SATB1. Both staining patterns tended to have opposite roles in the prognosis of PAC: SATB1 ${ }^{\mathrm{C}}$ was an independent prognostic factor for poor OS, whereas SATB1 ${ }^{\mathrm{n}}$ expression reached no statistical significance, but Kaplan-Meier curves separated patients with low expression and adverse prognosis from patients with high expression and favorable prognosis. High levels of SATB1 mRNA appeared as an independent prognostic indicator for better OS. Furthermore, individual expression of SMAD3 or Ezrin, as well as combined expression of SATB1/SMAD3/Ezrin/ $\beta$-catenin, were associated with OS independently of conventional risk factors, both in our cohort and TCGA dataset. In our series, patients with tumors harboring combined expression of SATB1 ${ }^{\text {n-high }} /$ SMAD $^{\text {low }} /$ Ezrin $^{\text {low }} / \beta$-catenin ${ }^{\text {low }}$ experienced the highest survival rates, while those with SATB1 ${ }^{\text {c-present }} /$ SMAD $^{\text {high }} /$ Ezrin $^{\text {high }} / \beta$ catenin $^{\text {high }}$ had the worst survival. In conclusion, protein and/or mRNA expression levels of SATB1, SMAD3, Ezrin and $\beta$-catenin may serve as potential prognostic biomarkers for PAC, both as single predictors and even better when combined.
\end{abstract}

Keywords: pancreatic ductal adenocarcinoma; SATB1; SMAD3; Ezrin; $\beta$-catenin; prognostic factor

\section{Introduction}

Pancreatic cancer is one of the most aggressive and lethal malignant neoplasms worldwide. According to the Global Cancer Statistics 2020, pancreatic cancer is ranked as the 7th leading cause of cancer-related deaths, accounting for $4.7 \%$ of all diagnosed malignancy cases with increasing frequency [1]. Despite significant advances in the understanding of potential risk factors that cause pancreatic cancer and newly available tools for early diagnosis and treatment, the general 5-year survival rate for patients is lower than 9\% [2]. There are two main types of pancreatic cancer: pancreatic adenocarcinoma, known as pancreatic ductal adenocarcinoma (PDAC), which originates from the epithelium of a duct, and pancreatic neuroendocrine tumor arising from the abnormal growth of endocrine 
(hormone-producing) cells in the pancreas called islet cells [3]. PDAC is a type of exocrine pancreatic cancer and the most common type of pancreatic malignancies (more than $85 \%$ of all cases). This type is known for its extremely poor prognosis, with an overall 1-year mortality rate of $24 \%$ [2]. Undoubtedly, there is an urgent need for the development of a novel, more effective therapeutic regimen. Therefore, the identification of key oncogenic regulators and understanding of pathways involved in the pathogenesis and progression of pancreatic cancer is of high importance. A greater understanding of the relationship between biomarkers expression and the clinicopathological characteristics as well as patient survival would be useful from the clinical point of view.

Ezrin is a protein encoded by the EZR human gene. It is a principal member of the ezrin-radixin-moesin (ERM) family, which functions as a general cross-linker between membrane proteins and actin filaments. Ezrin exists in two conformations-dormant and active. The former exists in a closed form that mostly resides in the cytoplasm, and the latter is an open form localized mainly at the plasma membrane. It is widely established that Ezrin is frequently overexpressed in invasive cancers, which is related to a poor prognosis. The results of several studies suggest that Ezrin may regulate various signaling pathways and molecules involved in tumor progression [4-6].

SMAD family member 3 (SMAD3) acts through transforming growth factor-beta (TGF- $\beta$ ). The protein participates in the regulation of gene activity, cell proliferation, differentiation and death [7]. However, the SMAD3-mediated TGF- $\beta$ signaling pathway is also involved in the induction of tumor angiogenesis and the promotion of tissue invasion and metastasis $[8,9]$.

The many cellular processes, including organ development, differentiation and tissue homeostasis, are controlled by the Wnt/ $\beta$-catenin signaling pathway. Aberrant Wnt $/ \beta$ catenin signaling can lead to developmental defects and cancer progression. $\beta$-catenin (encoded by CTNNB1 gen) is a key molecule in this pathway. Stabilized $\beta$-catenin accumulates in the cytoplasm and translocates to the nucleus, where it binds the TCF/LEF family members and induces the transcription of target genes. Many studies have reported that overexpression of $\beta$-catenin is associated with several human cancers [10-12]. However, the role of $\beta$-catenin expression in PDAC is somewhat controversial [13].

Special AT-rich sequence-binding protein 1 (SATB1) is a higher-order chromatin organizer and a global transcriptional regulator. SATB1 may regulate whole sets of genes, even those located on distant chromosomes, by altering the functional organization of the DNA sequence. In addition, SATB1 is engaged in post-transcriptional modifications, such as phosphorylation or acetylation, conferring its ability to act as a repressor or activator of gene expression [14]. SATB1 is known to play a vital role in the differentiation, embryonic development and maturation of thymocytes [15]. Furthermore, our team has revealed that the SATB1/F-actin complex is involved in the active cell death of both tumor [16] and non-tumor cells [17]. However, it may also contribute to tumor progression and metastasis. Many recent studies have shown that the abnormal expression of SATB1 is frequently associated with clinicopathological features and patient survival, but its clinical value in PDAC is still underexplored [18-24].

Similar to other malignancies, uncontrolled cell proliferation is induced in PDAC by the alternating function of different intracellular signaling pathways' components. As demonstrated in previous studies, SATB1, SMAD3, Ezrin and $\beta$-catenin play an important role in regulating cell proliferation, migration and apoptosis, which are strongly implicated in carcinogenesis. In this study, we selected these proteins due to the fact that they may be related by their respective roles and overlapping signaling cascades in tumor cells; however, their joint expression has not been previously evaluated in clinical samples of PDAC. Therefore, the aim of this research was to explore the prognostic value of the single and combined expression of SATB1, SMAD3, Ezrin and $\beta$-catenin in PDAC. Protein expression was evaluated by immunochemistry in the institutional tissue macroarrays (TMAs), while mRNA expression used publicly available TCGA data. Both were correlated with clinicopathological parameters and patient outcome (overall survival, OS). Finally, 
protein-protein interaction (PPI) network for $\beta$-catenin, Ezrin, SATB1, SMAD3 and their 50 neighbors was constructed and functionally annotated to predict biological functions and pathways possibly related to examined factors in PAC.

\section{Materials and Methods}

\subsection{Patients and Tissue Specimens}

The research was performed on formalin-fixed paraffin-embedded tissue (FFPE) specimens from 68 patients with PDAC who were operated at the Department of Liver and General Surgery, Collegium Medicum in Bydgoszcz, Nicolaus Copernicus University in Torun (Poland). Histopathological diagnosis for each tumor sample was confirmed by two independent pathologists, based on the hematoxylin and eosin (HE) staining in the Department of Clinical Pathomorphology, Collegium Medicum in Bydgoszcz. All tumors were reclassified according to the standardized TNM 8th edition classification of The American Joint Committee on Cancer (AJCC) criteria. To avoid excessive study complexity, the cohort included only adenocarcinomas, and all other histological types were excluded from the series. All clinical data were systematized and analyzed in detail. The study group included 68 patients (34 female, 34 male) with an average age of 63 years (range 43-81). The most common tumor location was the head of the pancreas $(n=60,88.24 \%)$. In turn, pancreatic body and tail tumors were less frequent $(n=8,11.77 \%)$. Considering a histological grade, 5 samples were classified as differentiated (G1;7.35\%), 55 as moderately differentiated (G2; $80.88 \%$ ), and 8 as poorly differentiated (G3; 11.77\%) cancer tissue. Regarding pathologic T stage, the study group consisted of $10 \mathrm{~T} 1$ (14.71\%), 43 T2 (63.24\%), 8 T3 (11.77\%), 2 T4 $(2.94 \%)$ and $5 \mathrm{Tx}(7.35 \%)$ cases. Thirty-six (52.94\%) patients were characterized by a positive and $30(44.12 \%)$ by a negative lymph node status (no data for 2 patients). Perineural invasion was present in 42 (61.77\%) patients, while vascular invasion was confirmed for $23(37.10 \%)$ patients. Data concerning postsurgical survival were available for 62 patients, and the median follow-up time was 1427 days. The study was carried out using the same tissue specimens as in our previously published study [25], whereby the final follow-up was extended to 6 September 2020. The control tissue $(n=64)$ was from 54 of the 68 PDAC patients with the adjacent normal pancreatic tissue and another 10 specimens from normal peritumoral tissue of other PDAC patients. The study protocol has been approved by The Ethics Committee of Nicolaus Copernicus University in Torun, Ludwik Rydygier Collegium Medicum in Bydgoszcz (approval number KB 342/2020).

\subsection{Tissue Macroarrays and Immunohistochemical Staining}

Representative tumor areas (tumor areas with at least $80 \%$ of tumor cells) and the adjacent areas of histologically normal tissue were selected in order to obtain tissue macroarray. Tissue macroarrays were obtained by transferring representative large tissue fragments from donor blocks into a new recipient block. One recipient block included 5 different tumor samples from donors' paraffin blocks. For verification tumor cells in tissue macroarray blocks, HE staining was performed. IHC studies were carried out on FFPE specimens at the Department of Clinical Pathomorphology, Collegium Medicum in Bydgoszcz, Nicolaus Copernicus University in Torun, Poland. Selected paraffin blocks were cut into 3-4 $\mu \mathrm{m}$ thick sections using a manual rotary microtome (Accu-Cut, Sakura, Torrance, CA, USA). Subsequently, paraffin sections were placed on extra adhesive slides (SuperFrost Plus; Menzel-Glaser, Braunschweig, Germany) and dried at $60^{\circ} \mathrm{C}$ for $1 \mathrm{~h}$. Next, sections were deparaffinized and rehydrated. Antigen retrieval was performed using a high-pH buffer (Dako; Agilent Technologies, Inc., Santa Clara, CA, USA) at $95-98{ }^{\circ} \mathrm{C}$ for $20 \mathrm{~min}$ in an automated PT-link system (Dako). Automated immunostaining for anti-SATB1 antibody (ab109122, Abcam, Great Britain), anti-SMAD3 antibody (ab28379, Abcam), anti-Ezrin antibody (ab41672, Abcam) and anti- $\beta$-catenin antibody (ab32572, Abcam) was carried out with EnVision FLEX+ HRP reagents (Dako). Endogenous peroxidase activity, as well as the nonspecific binding sites, were blocked by incubation with $3 \% \mathrm{H}_{2} \mathrm{O}_{2}$ for $10 \mathrm{~min}$ at room temperature (RT) and 3\% bovine serum albumin (BSA) for $15 \mathrm{~min}$ at RT, respec- 
tively. Tissue sections were then incubated with primary rabbit polyclonal anti-SATB1 antibody (1:200), primary rabbit polyclonal anti-SMAD3 antibody (1:500), primary rabbit polyclonal anti-Ezrin antibody (1:100) and primary rabbit monoclonal anti- $\beta$-catenin antibody (1:100) for $30 \mathrm{~min}$ at RT. Finally, slides were incubated with EnVisionFlex+ AntiMouse/Rabbit HRP-Labeled Polymer (Dako) for 20 min. The staining signal was developed with 3,3'diaminobenzidine (DAB) solution. Tissues sections were counterstained with hematoxylin and dehydrated in ethanol of increasing concentration (80, 90, 96, 99.8\%), then cleared in a series of xylenes (from I to IV). Finally, the slides were sealed with Dako mounting medium.

\subsection{Evaluation of Immunohistochemistry Staining}

The IHC evaluation of protein expression was performed by two independent pathologists in the light ECLIPSE E400 microscope (Nikon Instruments Europe, Amsterdam, Netherlands) at $20 \times$ original objective magnification. Each core was evaluated randomly in three areas with obvious lesions.

The immunoexpression of studied proteins was evaluated according to the modified Index Remmele-Stegner (IRS) by multiplying the percentage of positively stained cells/areas and staining intensity. The percentage of positive cells/area was scored in the following way: (0)—less than $10 \%$, (1)-11-20\%, (2)-21-50\%, (3)-51-80\% and (4) - equal or more than $81 \%$, and the intensity of the stain was scored using the following criteria: (0)—negative; (1)—weak staining; (2)—moderate staining; and (3)—strong staining. The final staining result, ranging from 0 to 12, was divided into two expression groups based on a specific discrimination threshold set by the Evaluate Cutpoints software [26]. The cut-off values for high and low expression of nuclear SATB1 (SATB1 ${ }^{\mathrm{n}}$ ), SMAD3, Ezrin and $\beta$-catenin were as follows: $<1 ; \geq 1,<8 ; \geq 8,<8 ; \geq 8,<4 ; \geq 4$, respectively. Cytoplasmic SATB1 $\left(\mathrm{SATB}^{\mathrm{C}}\right)$ expression was scored as positive or negative based on the presence $(+)$ or absence $(-)$ of cytoplasmic tumor cell staining. Combined prognostic values of candidate biomarkers were evaluated in the following expression groups: cases with the co-expression of SATB1 ${ }^{\text {n-low }} S M A D 3^{\text {high }}$ Ezrin high $\beta$-catenin ${ }^{\text {high }}$ were analyzed in comparison with the opposite expression pattern (SATB1 ${ }^{\text {n-high }}$ SMAD $3^{\text {low }} \operatorname{Ezrin}^{\text {low }} \beta$-catenin ${ }^{\text {low }}$ ), whereas "other" defined all else expressive cases (the reference group); a similar scheme was followed for the co-expression of SATB1 $1^{\text {c-present }}$ SMAD ${ }^{\text {high }}{ }^{\text {Ezrin }}{ }^{\text {high }} \beta$-catenin ${ }^{\text {high }}$.

\subsection{In Silico Analysis}

To support our results and confront them with online available data, we additionally assessed SATB1, SMAD3, EZR and CTNNB1 expression in the TCGA cohort. Gene expression data for The Cancer Genome Atlas (TCGA) and Genotype-Tissue Expression (GTEx) cohorts from 177 patients with pancreatic adenocarcinoma (146 with ductal histology) and 165 of non-cancerous pancreatic tissues were obtained from www.cBioPortal.org and UCSC Xena Viewer (http:/ / xena.ucsc.edu/, accessed on 3 July 2020). The RNA sequencing datasets (RNA-seq) were normalized via DESeq2 normalization, and data were divided into low- and high-expression groups according to the cutpoints established in Evaluate Cutpoints software. The cut-off values for positive (high) and negative (low) expression of SATB1, SMAD3, EZR, CTNNB1 mRNA were as follows: $<10.99 ; \geq 10.99,<12.67 ; \geq 12.67$, $<14.35 ; \geq 14.35,<14.68 ; \geq 14.68$, respectively. We created the expression combination of the factors tested. Cases with the co-expression of SATB1 ${ }^{\text {low }}$ SMAD $3^{\text {high }}{ }^{2} Z R^{\text {high }} C T N N B 1^{\text {high }}$ were analyzed in comparison with the opposite expression pattern, whereas "other" defined all else expressive cases.

\subsection{Protein-Protein Interaction (PPI) Network Construction and Functional Enrichment Analysis}

The 50 neighboring genes most relevant to the queried genes (CTNNB1, EZR, SATB1 and $S M A D 3$ ) were filtered through the Search Tool for the Retrieval of Interacting Genes (STRING) database (https:/ / string-db.org, accessed on 14 September 2021) and further used to construct a network map, which was visualized via Cytoscape software version 
3.8.2. The cut-off criteria to construct the protein-protein interaction (PPI) network was set as confidence score $\geq 0.4$ and the maximum number of interactors $=50$. The most significant modules in the PPI network were identified using the Cytoscape plugin Molecular Complex Detection (MCODE) [27]. The screening options were set as degree cutoff $=2$, max. depth $=100, \mathrm{k}$-core $=2$ and node score cut-off $=0.2$. The top 10 genes in the network were screened as hub genes using the degree method with the CytoHubba plugin [28] in Cytoscape software. Pathway analysis and visualization were performed using the Reactome Pathway database (https: / / reactome.org, accessed on 14 September 2021) [29]. To find KEGG Pathway and Gene Ontology (GO) categories (cellular component (CC), biological process (BP) and molecular function (MF)) shared by the analyzed genes, the Database for Annotation, Visualization and Integrated Discovery (DAVID; https: / / david.ncifcrf.gov, accessed on 14 September 2021) [30] was applied. The KEGG BRITE (https:/ / www.genome.jp/kegg/brite.html, accessed on 14 September 2021) [31] was utilized to explore functional hierarchies of the imputed genes.

\subsection{Statistical Analysis}

Statistical analyses were performed using GraphPad Prism version 7.01 (GraphPad Software, La Jolla, CA, USA) and SPSS version 26.0 software (IBM Corporation, Armonk, NY, USA). The Mann-Whitney test was used to compare continuous variables, and Fisher's exact or Chi-squared tests were used to compare the categorical variables. To assess the correlations between the expression of SATB1, SMAD3, Ezrin/EZR and $\beta$-catenin/CTNNB1, Spearman's correlation coefficient was employed. Survival outcomes were assessed using the Kaplan-Meier method, and differences were evaluated using the log-rank test. Univariate and multivariate survival analyses were performed using the Cox proportional hazard regression model. Additionally, 95\% confidence intervals (95\% CIs) and the hazard ratios (HRs) were calculated. Variables that had a significant relation to OS in the univariate analysis were introduced into the multivariate Cox regression model. The $p$ value $<0.05$ was considered statistically significant.

\section{Results}

3.1. Comparison of Protein Expression in Cancer and Normal Tissue and Its Relation to Clinicopathological Characteristics in Our Cohort

The study included the analysis of the expression of four proteins-SATB1, SMAD3, Ezrin and $\beta$-catenin. Representative images of IHC staining are presented in Figure 1A-J. Comparison of SATB $1^{\mathrm{n}}$ expression between PDAC and healthy tissue margin indicated a statistically significant reduction in PDAC positive samples $(p<0.0001$; Figure $2 \mathrm{~A})$. Interestingly, in the case of cancer tissue, in 21 cases $(30.88 \%)$, cytoplasmic labeling was also present, which was not observed in any of the control samples $(p<0.0001$; Figure $2 \mathrm{~B})$. Fifty-two samples (76.47\%) of tumor tissue were characterized by low and $16(23.53 \%)$ by high SATB1 ${ }^{\mathrm{n}}$ expression. SATB1 ${ }^{\mathrm{n}}$ did not correlate with histological type, age, stage, pT and $\mathrm{pN}$ status. However, we found its correlation with histological grade. Low SATB1 ${ }^{\mathrm{n}}$ expression was observed in $100 \%$ of G1 tumors $(n=5), 78.18 \%$ of G2 $(n=55)$ tumors and $50 \%$ of G3 tumors $(n=8)$, and these differences were statistically significant $(p=0.03)$. $\mathrm{SATB}^{\mathrm{c}}$ did not correlate with histological type, age, histological grade, stage or $\mathrm{pT}$ and $\mathrm{pN}$ status (Table 1). 

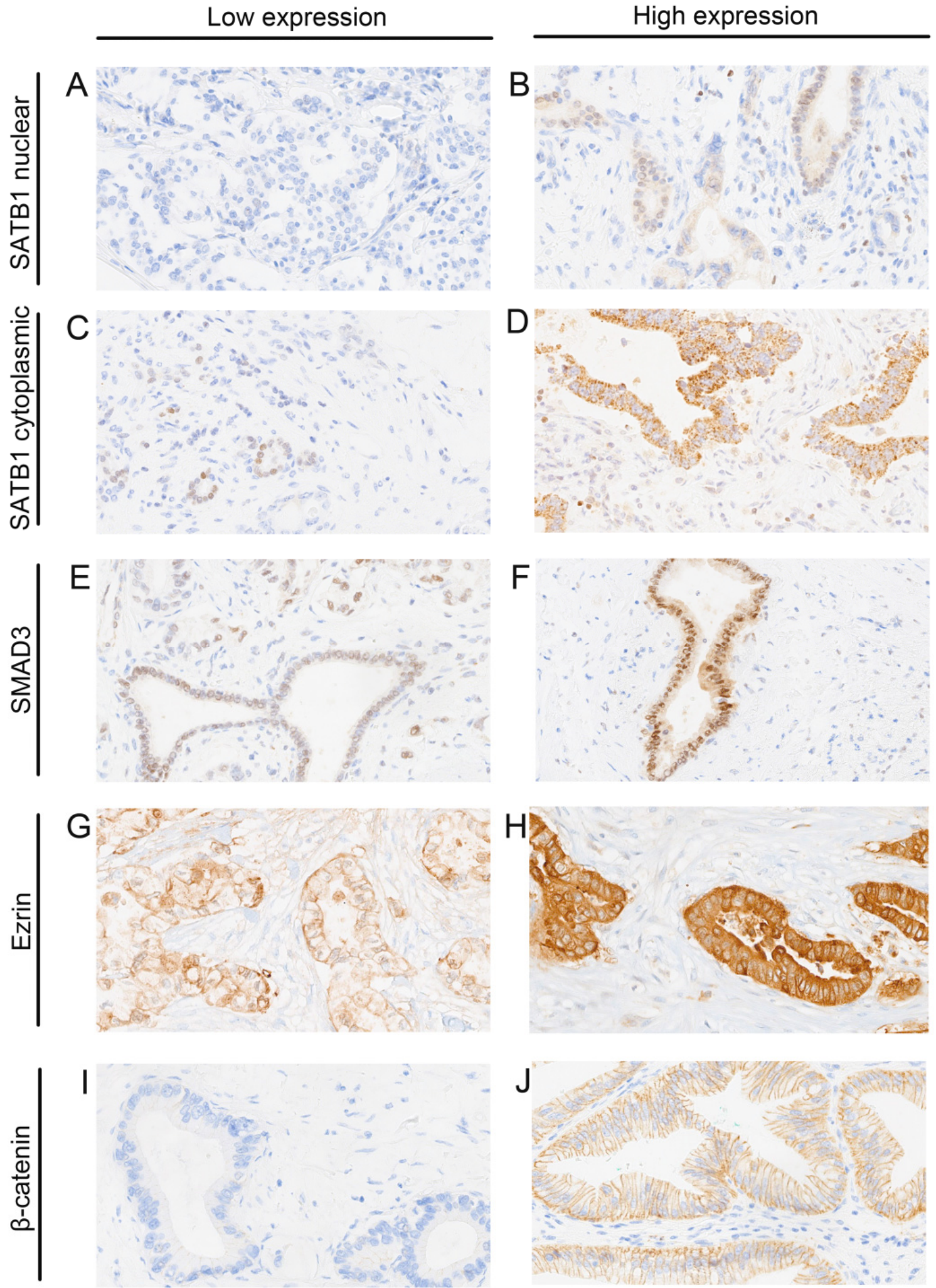

Figure 1. Representative images of immunohistochemical expression of nuclear SATB1 (A,B), cytoplasmic SATB1 (C,D), SMAD3 (E,F), Ezrin $(\mathbf{G}, \mathbf{H})$ and $\beta$-catenin $(\mathbf{I}, \mathbf{J})$ in pancreatic ductal adenocarcinoma. Primary magnification $\times 20$. 
A

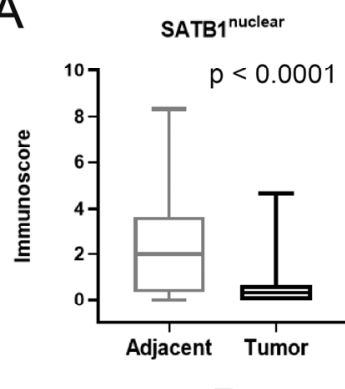

B

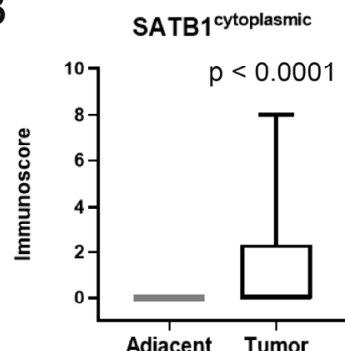

C

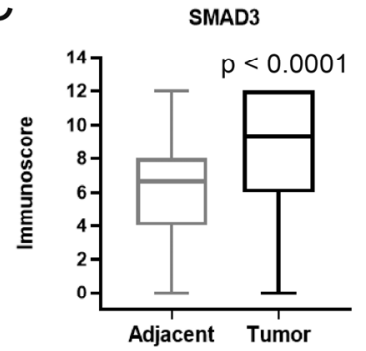

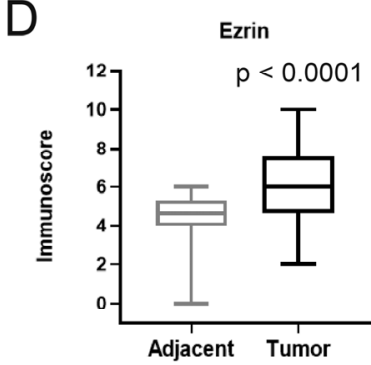

$\mathrm{E}$

B-catenin

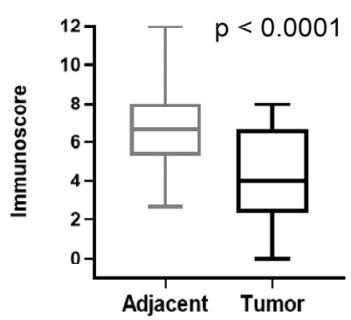

Figure 2. Comparison of the immunohistochemical expression of nuclear SATB1 (A), cytoplasmic SATB1(B), SMAD3 (C), EZR (D) and $\beta$-catenin (E) in tumor and adjacent tissues of PDAC patients.

Considering the available literature data and the obtained results regarding SMAD3, only its nuclear expression pattern was included. For both normal tissue margin and tumor samples, SMAD3 expression was confirmed in most of the cases $(96.88 \%$ for control and $98.53 \%$ for tumor specimens). However, its level was significantly increased in the case of PDAC samples compared to the adjacent tissue $(p<0.0001$; Figure $2 C)$. The adopted division allowed for the determination of 26 samples (38.24\%) with low and $42(61.77 \%)$ with high expression. The expression of SMAD3 did not correlate with histological type, histological grade, age, stage or $\mathrm{pT}$ and $\mathrm{pN}$ status (Table 1).

In the case of Ezrin, the dominant expression pattern for tumor samples was membranouscytoplasmic $(n=55,80.88 \%)$. Cytoplasmic without membrane labeling was visible for 13 samples (19.12\%). In contrast, in normal tissue, the membrane-cytoplasmic pattern was observed only for 28 specimens $(n=28,45.16 \%)$, while the most common was the cytoplasmic one $(100 \%)$. As shown in Figure 2D, compared to the adjacent tissue, tumor samples were characterized by significantly increased expression of Ezrin $(p<0.0001)$. In addition, overexpression of the protein was observed in 15 samples $(22.06 \%)$, while low expression was for $53(77.94 \%)$. The expression of Ezrin did not correlate with histological type, histological grade, age, stage and $\mathrm{pN}$ status. However, we found its correlation with pT status ( $p=0.048$; Table 1). Ezrin overexpression was markedly more frequent in the T3-T4 group $(n=5,50.00 \%)$ than T1-T2 $(n=10,18.87 \%)$.

For $\beta$-catenin, the membrane expression pattern was assessed. In normal tissue, membrane expression was observed in all $(100 \%)$ samples. In turn, for tumor tissue, membrane expression was present for $61(89.71 \%)$ cases. Comparison between control and tumor tissues showed a statistically significant decrease in the $\beta$-catenin expression in PDAC specimens $(p<0.0001$; Figure 2E). Twenty-five cancer tissue specimens were characterized by low $(36.77 \%)$ and 43 by high membrane expression (63.24\%). The expression of $\beta$-catenin did not correlate with histological type, histological grade, age, stage or $\mathrm{pT}$ and $\mathrm{pN}$ status (Table 1). 
Table 1. Immunohistochemical expression of SATB1 ${ }^{\mathrm{n}}$, SATB1 ${ }^{\mathrm{c}}$, SMAD3, Ezrin and $\beta$-catenin proteins and their relationship with clinicopathological features of PDAC patients.

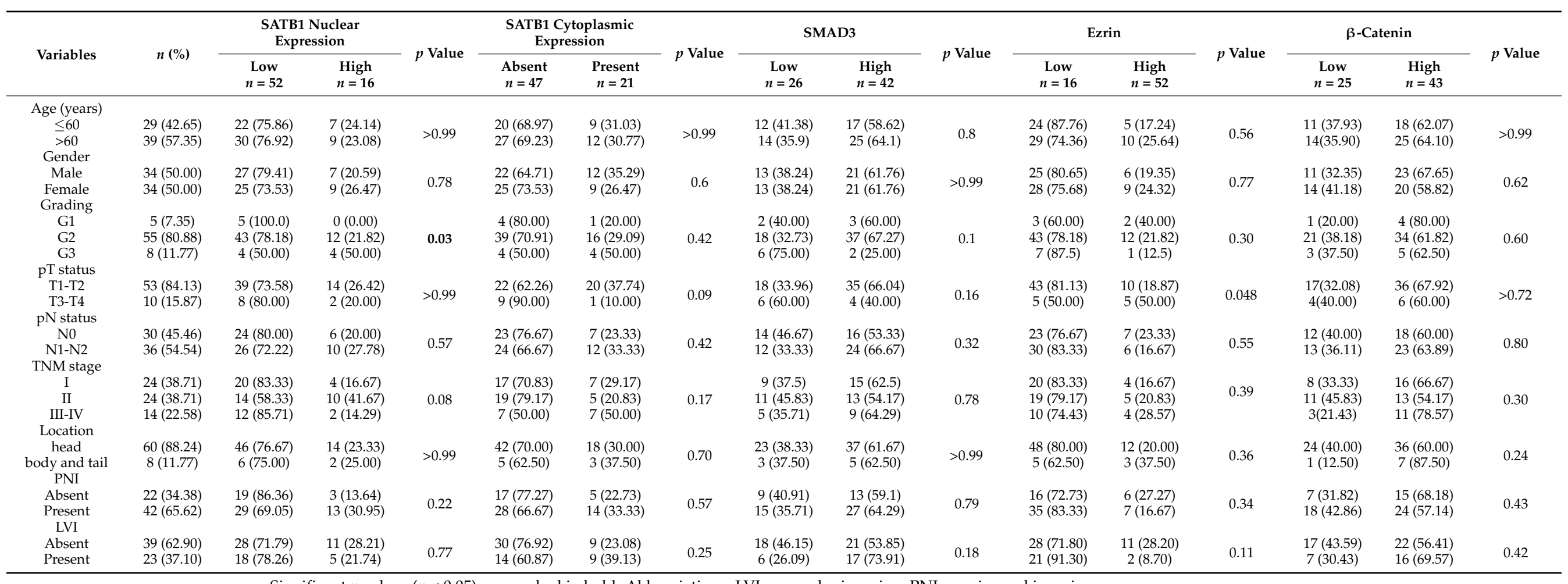




\subsection{Association between the Protein Expression and Patient Survival in Own Cohort}

Next, we constructed Kaplan-Meier curves to determine the impact of individual expression patterns of the studied proteins on the overall survival (OS) of PDAC patients. A suggestive association was observed between SATB $1^{\mathrm{n}}$ expression and OS, but without statistical significance (297 days vs. 561 days, $p=0.118$; Figure 3A). Notably, the presence of SATB1 ${ }^{\mathrm{C}}$ expression in PDAC was associated with a significantly shorter OS rate (median OS: 117 days) than the absence of SATB1 ${ }^{\mathrm{C}}$ expression (median OS: 458 days; $p=0.036$; Figure 3B). Combining these two staining patterns of SATB1 did not improve the survival prediction (Figure S1, Tables S1 and S2). Furthermore, Kaplan-Meier survival analysis indicated that PDAC patients with a high level of SMAD3 expression (median OS: 290 days) had lower OS rates $(p=0.004)$ than those with SMAD3 low expression level (median OS: 531 days, Figure 3C). Analysis of patient survival data also showed that low Ezrin expression correlated with a higher OS rate (median OS: 450 days) than high expression (median OS:118 days). This survival difference was of borderline significance ( $p=0.055$, Figure 3D). Low $\beta$-catenin expression tended to be associated with longer survival (median OS: 450 days) than high (median OS: 274 days; $p=0.088$, Figure 3E).
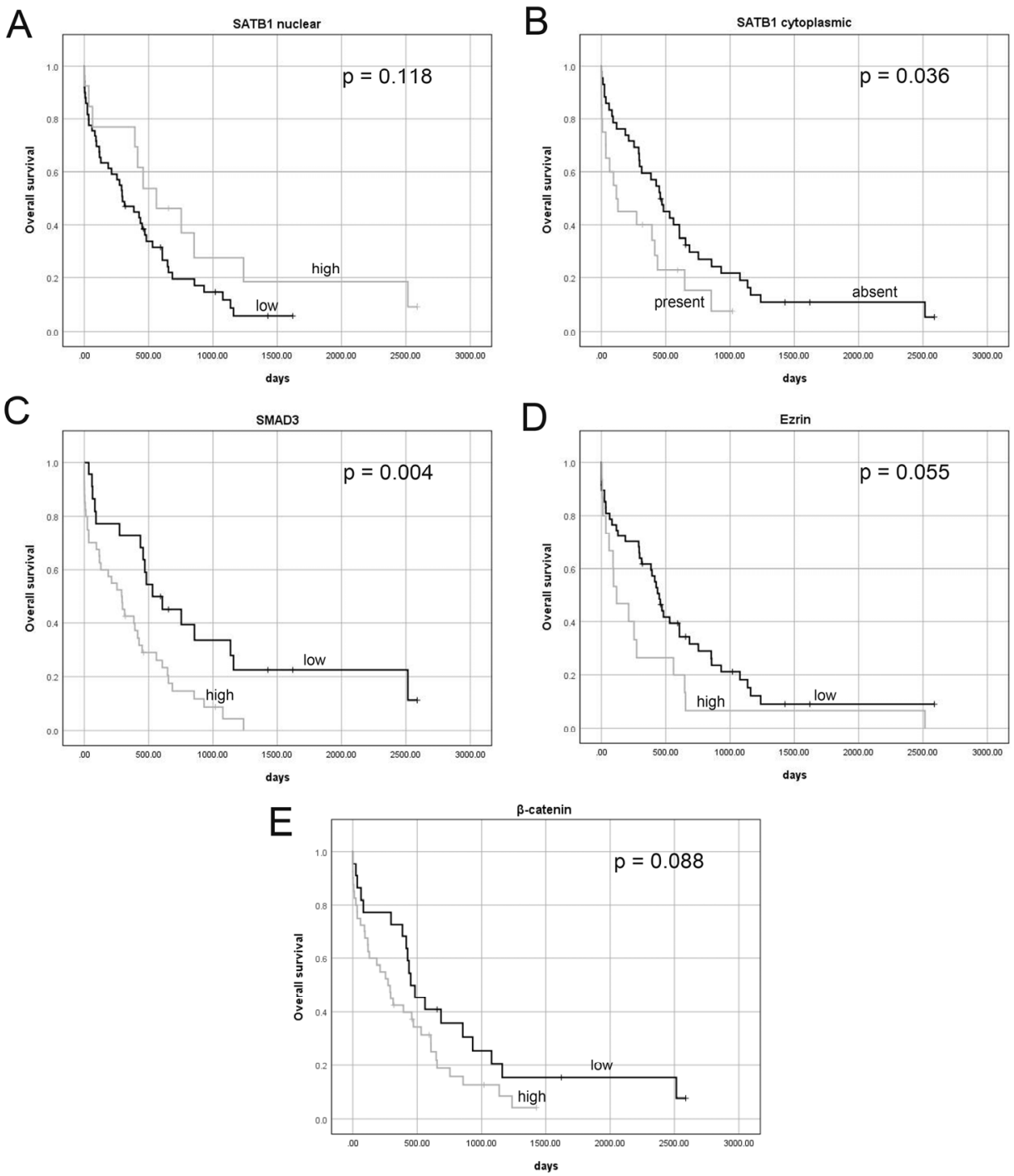

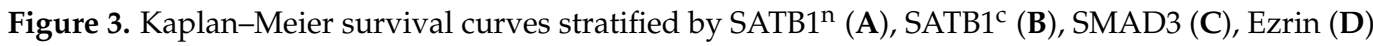
and $\beta$-catenin (E) expression in pancreatic adenocarcinoma. Protein expression was measured using immunohistochemistry, and the calculated IRS scores were divided into two categories as specified in the Material and methods. 


\subsection{Significance of Assessed Characteristics as Prognostic Factors in Own Cohort}

To further examine the prognostic value of the studied proteins as single indicators, univariate and multivariate survival analyses were performed using the Cox proportional hazard regression model. The univariate Cox analysis pointed to age $(p=0.04)$, TNM stage $(p=0.03)$, vascular invasion $(p=0.01)$, SATB1 ${ }^{\mathrm{C}}(p=0.039)$ and SMAD3 $(p=0.005)$ as significant prognostic factors for OS in PDAC patients. In turn, Ezrin expression reached borderline significance $(p=0.06)$. After adjusting for classical prognostic factors using the multivariate Cox regression analysis, the strength of this association increased and was statistically significant $(p=0.01)$. Furthermore, the multivariate analysis confirmed the significance of high SMAD3 expression (HR 3.08, 95\% CI 1.52-6.23, $p=0.002$ ) as an independent negative prognostic factor for PDAC patients. Moreover, $\mathrm{SATB} 1^{\mathrm{C}}$ expression was indicated as an independent poor prognostic factor of near significance (HR 1.86, 95\% CI $0.93-3.74, p=0.08$ ) after adjustment for age, TNM stage and LVI. The results of univariate and multivariate Cox analyses are shown in Tables 2 and 3, respectively.

Table 2. Univariate analysis of prognostic factors by Cox proportional hazard model in own cohort.

\begin{tabular}{|c|c|c|c|c|}
\hline \multicolumn{5}{|c|}{ Univariate Analysis of Own Cohort } \\
\hline \multirow{2}{*}{ Variable } & \multirow{2}{*}{ HR } & \multicolumn{2}{|c|}{$95 \%$ CI } & \multirow{2}{*}{$p$ Value } \\
\hline & & Lower & Upper & \\
\hline SATB $1^{\mathrm{n}}$ & 1.73 & 0.86 & 3.47 & 0.12 \\
\hline SATB1 ${ }^{\mathrm{c}}$ & 1.87 & 1.03 & 3.40 & 0.039 \\
\hline SMAD3 & 2.40 & 1.31 & 4.40 & 0.005 \\
\hline Ezrin & 1.80 & 0.98 & 3.30 & 0.06 \\
\hline$\beta$-catenin & 1.64 & 0.92 & 2.92 & 0.09 \\
\hline age & 1.03 & 1.00 & 1.07 & 0.04 \\
\hline gender & 0.96 & 0.56 & 1.65 & 0.88 \\
\hline grading & 0.95 & 0.37 & 2.41 & 0.91 \\
\hline $\mathrm{pN}$ & 1.30 & 0.74 & 2.27 & 0.36 \\
\hline $\mathrm{pT}$ & 1.09 & 0.53 & 2.27 & 0.81 \\
\hline TNM stage & 2.08 & 1.09 & 3.98 & 0.03 \\
\hline PNI & 1.58 & 0.89 & 2.82 & 0.12 \\
\hline LVI & 2.16 & 1.17 & 3.96 & 0.01 \\
\hline
\end{tabular}

Significant $p$ values $(p<0.05)$ are marked in bold. Abbreviations: $\mathrm{CI}$, confidence interval; HR, hazard ratio; LVI-vascular invasion; PNI-perineural invasion.

\subsection{Correlation between the Expression of SATB1, SMAD3, Ezrin and $\beta$-Catenin in Own Cohort}

A weak negative and significant association was found between the expression of $\beta$-catenin and SATB1 ${ }^{\mathrm{n}}(\mathrm{r}=-0.291, p=0.015)$. In addition, a weak positive and significant association was revealed between the expression of $\beta$-catenin and SMAD3 $(r=0.251$, $p=0.039$ ). Furthermore, moderate positive and significant association was confirmed between the expression of $\beta$-catenin and SATB1 ${ }^{\mathrm{C}}(\mathrm{r}=0.321, p=0.007)$. A weak positive association was also noted between the expression of SATB1 ${ }^{\mathrm{C}}$ and SMAD3, but this correlation did not reach statistical significance $(\mathrm{r}=0.214, p=0.08)$. 
Table 3. Multivariate analysis of prognostic factors by Cox proportional hazard model in own cohort.

\begin{tabular}{|c|c|c|c|c|c|c|c|c|c|c|c|c|c|c|}
\hline \multicolumn{15}{|c|}{ Multivariate Analysis of Own Cohort } \\
\hline \multirow{2}{*}{ Variable } & \multirow{2}{*}{ HR } & \multicolumn{2}{|c|}{$95 \%$ CI } & \multirow{2}{*}{$p$ Value } & \multirow{2}{*}{ Variable } & \multirow{2}{*}{ HR } & \multicolumn{2}{|c|}{$95 \%$ CI } & \multirow{2}{*}{$p$ Value } & \multirow{2}{*}{ Variable } & \multirow{2}{*}{ HR } & \multicolumn{2}{|c|}{$95 \% \mathrm{CI}$} & \multirow{2}{*}{$p$ Value } \\
\hline & & Lower & Upper & & & & Lower & Upper & & & & Lower & Upper & \\
\hline SATB $^{\mathrm{n}}$ & 1.19 & 0.56 & 2.55 & 0.66 & SATB1 $^{\mathrm{C}}$ & 1.86 & 0.93 & 3.74 & 0.08 & SMAD3 & 3.08 & 1.52 & 6.23 & 0.002 \\
\hline age & 1.04 & 1.00 & 1.08 & 0.03 & age & 1.05 & 1.01 & 1.10 & 0.015 & age & 1.05 & 1.01 & 1.09 & 0.024 \\
\hline $\begin{array}{l}\text { TNM } \\
\text { stage }\end{array}$ & 2.28 & 1.09 & 4.74 & 0.03 & $\begin{array}{l}\text { TNM } \\
\text { stage }\end{array}$ & 2.46 & 1.22 & 4.95 & 0.012 & $\begin{array}{l}\text { TNM } \\
\text { stage }\end{array}$ & 2.79 & 1.38 & 5.67 & 0.005 \\
\hline LVI & 2.59 & 1.33 & 5.02 & 0.005 & LVI & 2.76 & 1.40 & 5.43 & 0.003 & LVI & 2.71 & 1.38 & 5.30 & 0.004 \\
\hline \multirow{2}{*}{ Variable } & \multirow{2}{*}{ HR } & \multicolumn{2}{|c|}{$95 \%$ CI } & \multirow{2}{*}{$p$ Value } & \multirow{2}{*}{ Variable } & \multirow{2}{*}{ HR } & \multicolumn{2}{|c|}{$95 \%$ CI } & $n$ Valup & & & & & \\
\hline & & Lower & Upper & & & & Lower & Upper & $p$ varue & & & & & \\
\hline Ezrin & 2.70 & 1.25 & 5.85 & 0.011 & $\begin{array}{c}\beta- \\
\text { catenin }\end{array}$ & 1.69 & 0.86 & 3.32 & 0.13 & & & & & \\
\hline age & 1.05 & 1.01 & 1.09 & 0.013 & age & 1.05 & 1.01 & 1.09 & 0.016 & & & & & \\
\hline $\begin{array}{l}\text { TNM } \\
\text { stage }\end{array}$ & 2.11 & 1.04 & 4.27 & 0.038 & $\begin{array}{l}\text { TNM } \\
\text { stage }\end{array}$ & 2.32 & 1.16 & 4.64 & 0.017 & & & & & \\
\hline LVI & 3.55 & 1.74 & 7.26 & 0.001 & LVI & 2.64 & 1.35 & 5.15 & 0.004 & & & & & \\
\hline
\end{tabular}

Significant $p$ values $(p<0.05)$ are marked in bold. Abbreviations: CI, confidence interval; HR, hazard ratio; LVI-vascular invasion. HR: adjusting for age, TNM stage, VI.

3.5. Comparison of mRNA Expression in Cancer and Normal Tissue and Its Relation to Clinicopathological Characteristics in TCGA Cohort

In 177 PAC, based on the established cutpoint, high SATB1 mRNA expression of SATB1 mRNA was observed for 106 cases (59.89\%). There was no significant difference in the expression levels of SATB1 between PAC and normal pancreatic tissues $(p=0.9694$; Figure 4A). SATB1 level was dependent on $\mathrm{pN}$ status $(p=0.026)$. In the case of SMAD3 more samples were characterized by high expression $(n=103,58.19 \%)$ than low $(n=74,41.81 \%)$. The expression of SMAD3 mRNA was significantly higher in PAC tissues compared to normal pancreatic tissues ( $p<0.0001$; Figure $4 \mathrm{~B})$. SMAD3 expression correlated with grading $(p=0.012)$, pT status $(p=0.026)$ and TMN stage $(p=0.008)$. High EZR mRNA levels were found in $145(81.92 \%)$ PAC cases, whereas the remaining $32(18.08 \%)$ had low levels of this marker. The expression of EZR mRNA in PAC tissues was significantly up-regulated as compared with normal pancreatic tissues $(p<0.0001$; Figure $4 \mathrm{C})$. EZR level was dependent on grading $(p=0.02)$, pT status $(p=0.0157)$ and TNM stage $(p=0.0007)$. More of the patients were characterized by high CTNNB1 expression $(n=120,67.80 \%)$ than low $(n=57 ; 32.20 \%)$. Additionally, in the case of CTNNB1, its mRNA levels were significantly higher in PAC tissues compared to normal pancreatic tissues $(p<0.0001$; Figure 4D). The analysis showed statistically significant associations between CTNNB1 expression and grading $(p=0.001)$, pT status $(p=0.009), \mathrm{pN}$ status $(p=0.0002)$ and TMN stage $(p=0.0001)$. The described results are presented in Table 4 .
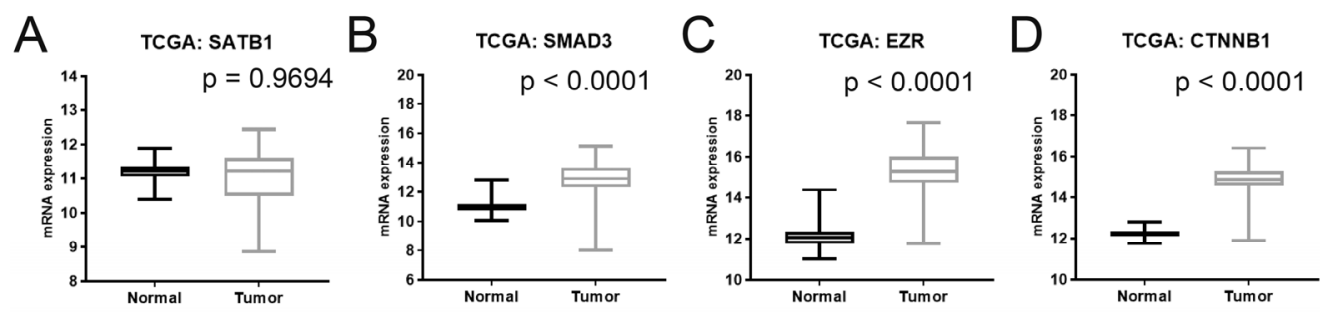

Figure 4. Comparison of mRNA expression levels of SATB1 (A), SMAD3 (B), Ezrin (C) and CTNNB1 (D) in tumor and normal tissues in PAC patients of TCGA cohort. 
Table 4. mRNA expression and its relationship with clinicopathological features of PAC patients in TCGA cohort.

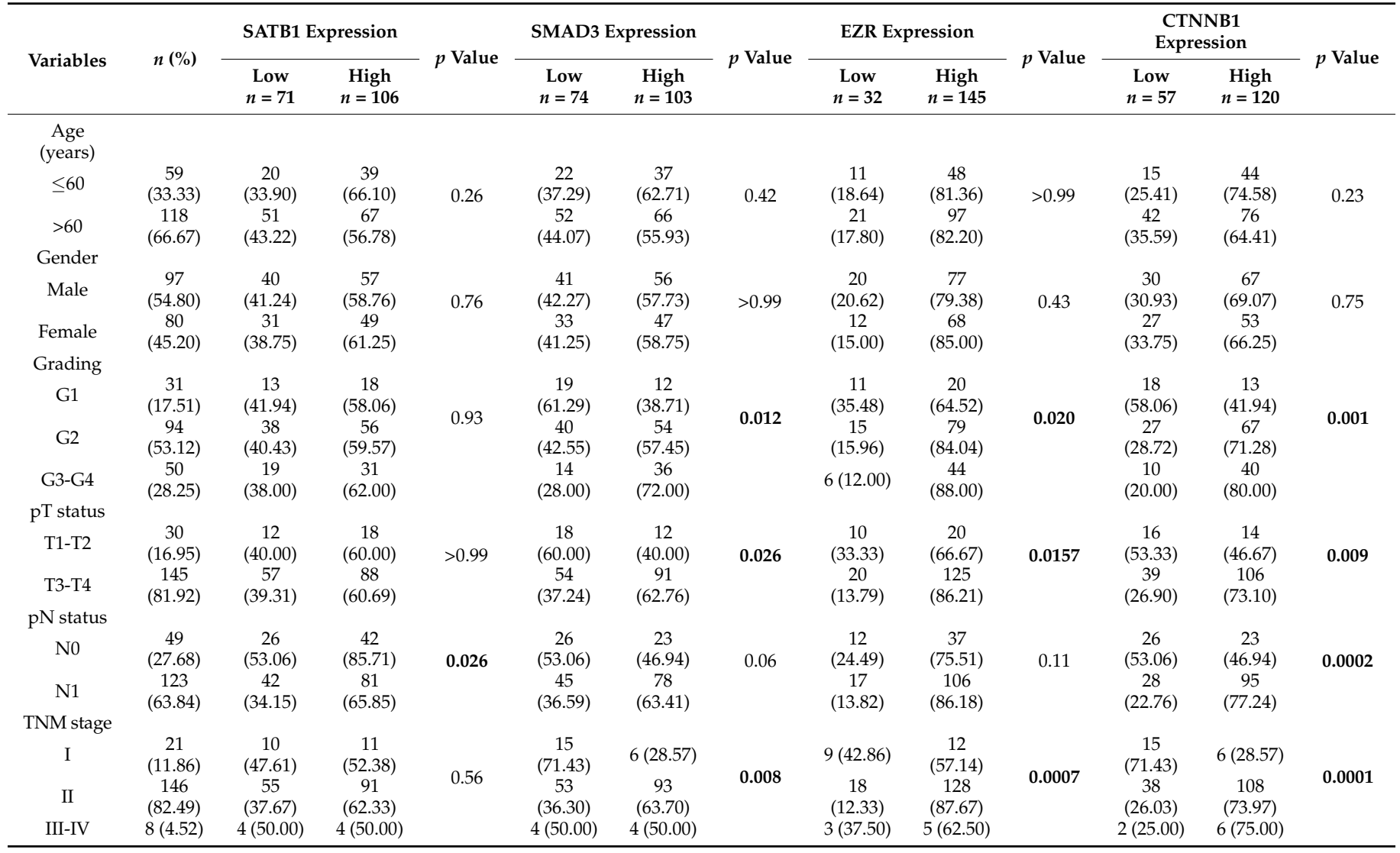

Significant $p$ values $(p<0.05)$ are marked in bold.

\subsection{Association between themRNA Expression and Patient Survival in TCGA Cohort}

Survival analysis of the TCGA cohort showed that SATB1 expression was not significantly correlated with OS (median OS for low vs. high expression $=517$ vs. $695, p=0.123$ ). While for SMAD3, EZR and CTNNB1, high expression was connected with a poorer survival rate (median OS for high vs. low expression $=498$ vs.1332, 592 vs. undefined and 592 vs. 2182, respectively). Except for $S A T B 1$, all the results were statistically significant $(p<0.0001$ for SMAD3 and EZR, and $p=0.0001$ for CTNNB1). Kaplan-Meier survival curves are presented in Figure 5.

\subsection{Significance of Assessed Characteristics as Prognostic Factors in TCGA Cohort}

The univariate Cox analysis showed that SMAD3 $(p<0.0001), E Z R(p<0.0001)$ and CTNNB1 $(p=0.002)$ expression levels were prognostic factors for OS of statistical significance, as well as age $(p=0.01)$, grading $(p=0.02), \mathrm{pN}(p=0.01)$ and $\mathrm{pT}$ status $(p=0.02)$. In turn, the multivariate analysis pointed to SATB1 $(p=0.002)$, SMAD3 $(p=0.05)$ and EZR $(p=0.033)$ expression as independent prognostic factors for OS. The obtained results are presented in Tables 5 and 6, respectively.

\subsection{Correlation between the Expression of SATB1, SMAD3, Ezrin and CTNNB1 in TCGA Cohort}

Spearman correlation coefficient statistics uncovered strong positive correlations between SMAD3 and EZR $(\mathrm{r}=0.757 ; p<0.0001)$ as well as between CTNNB1 and SMAD3 $(\mathrm{r}=0.606, p=0.0049)$. Moreover, a moderate positive and significant association was found between the expression of CTNNB1 and EZR $(\mathrm{r}=0.512, p<0.0001)$. A weak positive and significant association was also confirmed between the expression of SATB1 and CTNNB1 $(\mathrm{r}=0.244, p=0.001)$. There were no other connections between studied mRNAs. 
A

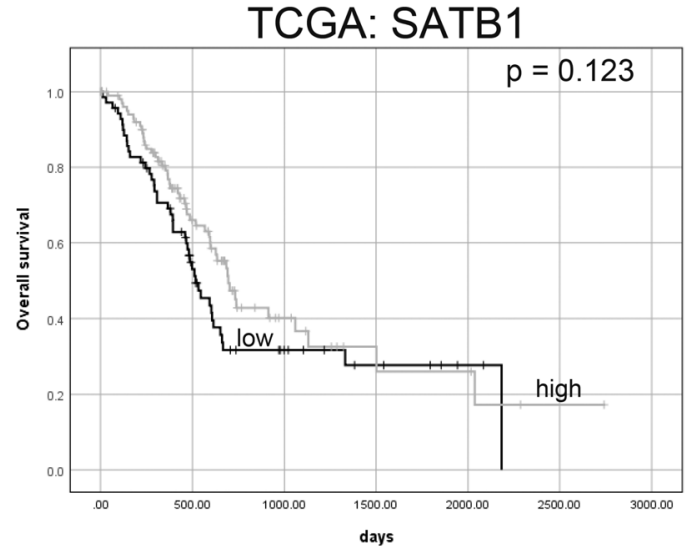

C

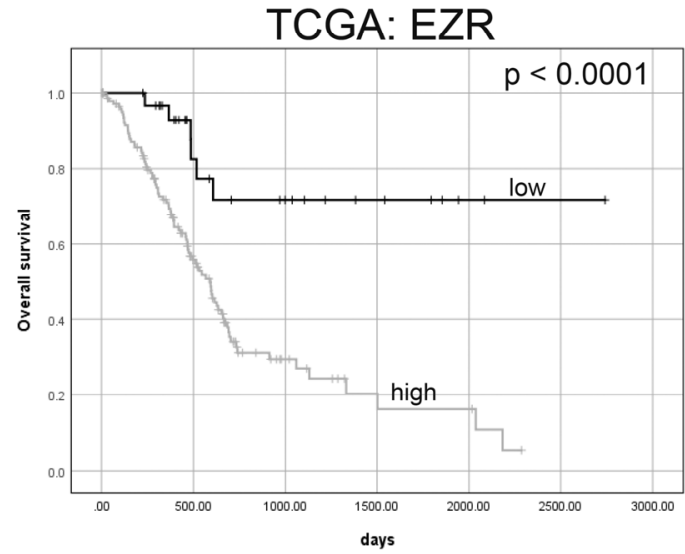

B

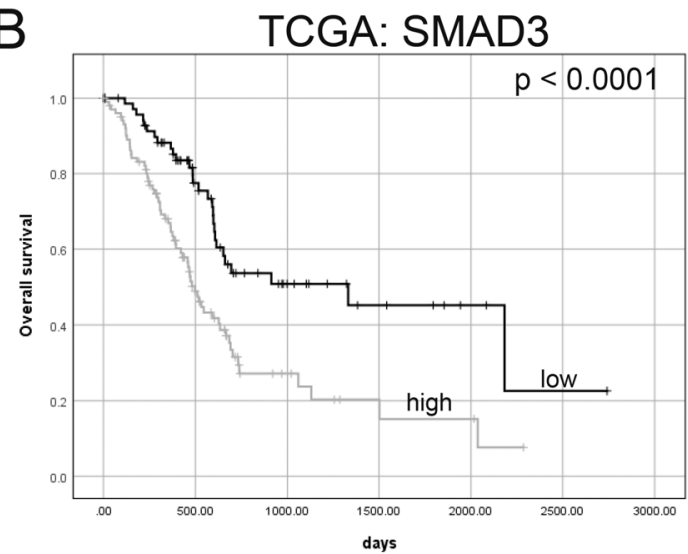

D

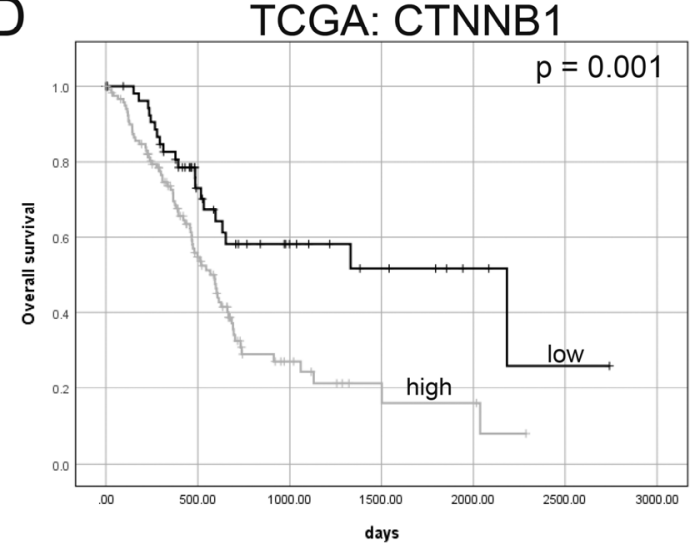

Figure 5. Kaplan-Meier survival curves stratified by SATB1 (A), SMAD3 (B), EZR (C) and CTNNB1 (D) mRNA levels in TCGA cohort.

Table 5. Univariate analysis of prognostic factors by Cox proportional hazard model in TCGA cohort.

\begin{tabular}{|c|c|c|c|c|}
\hline \multirow{3}{*}{ Variable } & \multicolumn{4}{|c|}{ Univariate Analysis of TCGA Cohort } \\
\hline & \multirow{2}{*}{ HR } & \multicolumn{2}{|c|}{$95 \% \mathrm{CI}$} & \multirow{2}{*}{$p$ Value } \\
\hline & & Lower & Upper & \\
\hline SATB1 & 0.73 & 0.48 & 1.09 & 0.12 \\
\hline SMAD3 & 2.26 & 1.45 & 3.54 & $<0.0001$ \\
\hline EZR & 4.65 & 2.02 & 10.69 & $<0.0001$ \\
\hline CTNNB1 & 2.21 & 1.34 & 3.65 & 0.002 \\
\hline age & 1.03 & 1.01 & 1.05 & 0.01 \\
\hline gender & 0.81 & 0.54 & 1.23 & 0.33 \\
\hline grading & 2.18 & 1.15 & 4.13 & 0.02 \\
\hline $\mathrm{pN}$ & 2.10 & 1.25 & 3.52 & 0.01 \\
\hline $\mathrm{pT}$ & 2.21 & 1.14 & 4.28 & 0.02 \\
\hline TNM stage & 0.74 & 0.23 & 2.34 & 0.60 \\
\hline
\end{tabular}

Significant $p$ values $(p<0.05)$ are marked in bold. Abbreviations: CI, confidence interval; HR, hazard ratio TCGA-The Cancer Genome Atlas. 
Table 6. Multivariate analysis of prognostic factors by Cox proportional hazard model in TCGA cohort.

\begin{tabular}{|c|c|c|c|c|c|c|c|c|c|}
\hline \multicolumn{10}{|c|}{ Multivariate Analysis of TCGA Cohort } \\
\hline \multirow{2}{*}{ Variable } & \multirow{2}{*}{ HR } & \multicolumn{2}{|c|}{$95 \% \mathrm{CI}$} & \multirow{2}{*}{$p$ Value } & \multirow{2}{*}{ Variable } & \multirow{2}{*}{ HR } & \multicolumn{2}{|c|}{$95 \%$ CI } & \multirow{2}{*}{$p$ Value } \\
\hline & & Lower & Upper & & & & Lower & Upper & \\
\hline SATB1 & 0.50 & 0.32 & 0.78 & 0.002 & SMAD3 & 1.57 & 0.99 & 2.49 & 0.05 \\
\hline age & 1.02 & 1.00 & 1.04 & 0.09 & age & 1.02 & 1.00 & 1.04 & 0.04 \\
\hline grade & 1.76 & 0.92 & 3.37 & 0.09 & grade & 1.51 & 0.79 & 2.89 & 0.21 \\
\hline $\mathrm{pN}$ & 2.53 & 1.42 & 4.52 & 0.0016 & $\mathrm{pN}$ & 1.77 & 1.02 & 3.09 & 0.04 \\
\hline $\mathrm{pT}$ & 1.32 & 0.64 & 2.72 & 0.46 & pT & 1.43 & 0.70 & 2.92 & 0.32 \\
\hline \multirow{2}{*}{ Variable } & \multirow{2}{*}{ HR } & \multicolumn{2}{|c|}{$95 \%$ CI } & \multirow{2}{*}{$p$ Value } & \multirow{2}{*}{ Variable } & \multirow{2}{*}{ HR } & \multicolumn{2}{|c|}{$95 \%$ CI } & $p$ Value \\
\hline & & Lower & Upper & & & & Lower & Upper & \\
\hline EZR & 2.50 & 1.07 & 5.83 & 0.033 & CTNNB1 & 1.42 & 0.83 & 2.45 & 0.20 \\
\hline age & 1.02 & 1.00 & 1.04 & 0.05 & age & 1.02 & 1.00 & 1.04 & 0.04 \\
\hline grade & 1.43 & 0.75 & 2.74 & 0.28 & grade & 1.54 & 0.81 & 2.94 & 0.19 \\
\hline $\mathrm{pN}$ & 1.83 & 1.06 & 3.17 & 0.030 & $\mathrm{pN}$ & 1.76 & 0.98 & 3.14 & 0.06 \\
\hline $\mathrm{pT}$ & 1.32 & 0.65 & 2.69 & 0.45 & $\mathrm{pT}$ & 1.39 & 0.68 & 2.86 & 0.37 \\
\hline
\end{tabular}

Significant $p$ values $(p<0.05)$ are marked in bold. Abbreviations: CI, confidence interval; HR, hazard ratio; TCGA-The Cancer Genome Atlas. HR: adjusting for age, grade, $\mathrm{pN}$ and $\mathrm{pT}$.

\subsection{Overall Survival Analysis According to the Combined Biomarker Expression}

Following the establishment of the significance of the investigated factors as single prognostic markers, we also examined the effect of their combined expression on OS in both our cohort and the TCGA cohort. Kaplan-Meier analysis revealed that the worst OS was observed in patients whose PDACs co-expressed SATB1 ${ }^{\text {c-present}}$ SMAD $3^{\text {high }}$ Ezrin $^{\text {high }} \beta$ catenin ${ }^{\text {high }}$. In turn, patients whose PDACs had opposite expression profiles of these proteins had significantly longer OS ( 8 vs. 1160 days; $p=0.001$; Figure $6 \mathrm{~B}$ ). In univariate (HR 3.06, 95\% CI 1.27-7.36, $p=0.01$; Table 7B) and multivariate (HR 7.32, 95\% CI 2.05-26.21, $p=0.002$; Table 8B) analyses, the combined SATB1 ${ }^{\text {c-present }}$ SMAD $3^{\text {high }}$ Ezrin $^{\text {high }} \beta$-catenin ${ }^{\text {high }}$ was a significant poor prognostic factor for OS with a particularly high hazard ratio when compared to each marker as a single indicator. Furthermore, SATB1 ${ }^{\mathrm{n}} / \mathrm{SMAD} 3 /$ Ezrin $/ \beta-$ catenin expression panel was significantly related to the duration of OS, with patients in the SATB $1^{\text {n-high }}$ SMAD $3^{\text {low }}$ Ezrin $^{\text {low }} \beta$-catenin ${ }^{\text {low }}$ expression group experiencing the longest survival (median overall survival not reached), whereas the opposite pattern of the expression panel predicted a poor survival (118 days, $p=0.023$; Figure 6 A). The SATB1 $1^{\text {n-high }}$ SMAD3 ${ }^{\text {low }}$ Ezrin $^{\text {low }} \beta$-catenin ${ }^{\text {low }}$ expression group was associated with a reduced risk of death by $89 \%$ after adjusting for age, tumor stage and LVI (HR 0.11, 95\% CI 0.01-0.93, $p=0.004$; Table 8A). In turn, in univariate and multivariate analysis, the crude and adjusted HRs were 2.16 (95\% CI 1.03-4.52, $p=0.04$ ) and 2.91 (95\% CI 1.07-7.91, $p=0.04)$, respectively, for SATB1 $^{\text {n-low }} /$ SMAD3 $^{\text {high }} /$ Ezrin $^{\text {high }} / \beta$-catenin ${ }^{\text {high }}$ expression group (Tables $7 \mathrm{~A}$ and $8 \mathrm{~A}$ ). 

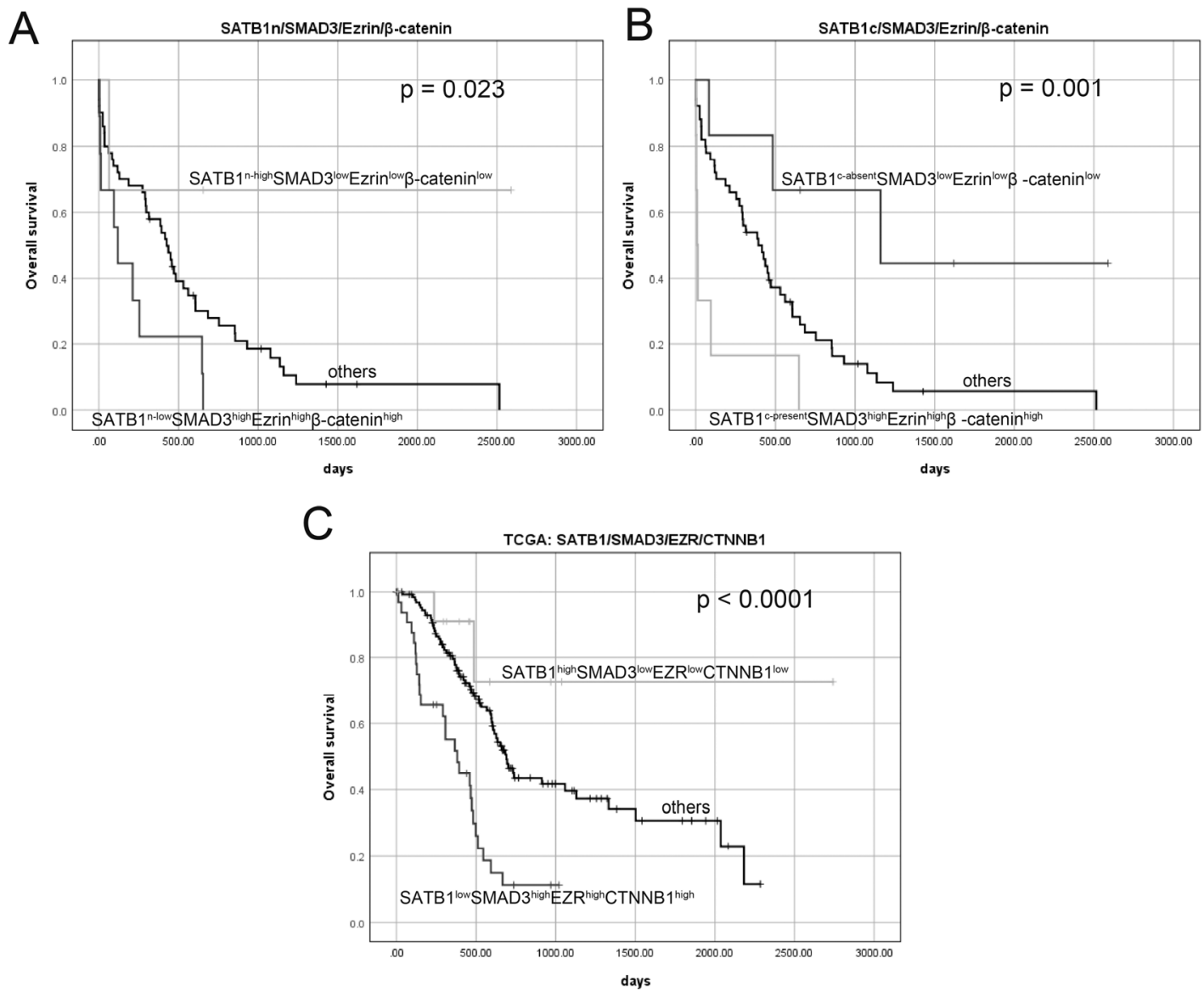

Figure 6. Overall survival analysis according to the combination of the panel (A) SATB1 ${ }^{\mathrm{n}} /$ SMAD3/Ezrin/ $\beta$-catenin, (B) SATB1 ${ }^{c}$ /SMAD3/Ezrin/ $\beta$-catenin and (C) TCGA: SATB1/SMAD3/ EZR/CTNNB1.

Table 7. Univariate analysis of prognostic factors by the Cox proportional hazard model for combined expression.

(A) Univariate Analysis of Own Cohort: SATB1 $/$ SMAD3/Ezrin/ $\beta$-Catenin

\begin{tabular}{|c|c|c|c|c|}
\hline \multirow{2}{*}{ Variable } & \multirow{2}{*}{ HR } & \multicolumn{2}{|c|}{$95 \% \mathrm{CI}$} & \multirow{2}{*}{$p$ Value } \\
\hline & & Lower & Upper & \\
\hline Others & \multicolumn{4}{|c|}{ Ref. } \\
\hline SATB1 $^{\text {n-high }}{ }^{\text {SMAD }}{ }^{\text {low }}$ Ezrin $^{\text {low }} \beta$-catenin ${ }^{\text {low }}$ & 0.21 & 0.03 & 1.60 & 0.13 \\
\hline SATB1 $^{\text {n-low }}$ SMAD $3^{\text {high }}$ Ezrin $^{\text {high }} \beta$-catenin high & 2.16 & 1.03 & 4.52 & 0.04 \\
\hline \multicolumn{5}{|c|}{ (B) Univariate Analysis of Own Cohort:SATB1'/SMAD3 /Ezrin/ $\beta$-Catenin } \\
\hline \multirow{2}{*}{ Variable } & \multirow{2}{*}{ HR } & \multicolumn{2}{|c|}{$95 \% \mathrm{CI}$} & \multirow{2}{*}{$p$ Value } \\
\hline & & Lower & Upper & \\
\hline Others & \multicolumn{4}{|c|}{ Ref. } \\
\hline SATB1 $^{\text {c-present }}$ SMAD $3^{\text {high }}$ Ezrin $^{\text {high }} \beta$-catenin ${ }^{\text {high }}$ & 3.06 & 1.27 & 7.36 & 0.01 \\
\hline SATB1 $^{\text {c-absent }}$ SMAD3 ${ }^{\text {low }}$ Ezrin $^{\text {low }} \beta$-catenin ${ }^{\text {low }}$ & 0.26 & 0.08 & 0.86 & 0.03 \\
\hline
\end{tabular}


Table 7. Cont.

(C) Univariate Analysis of TCGA Cohort: SATB1/SMAD3/EZR/CTNNB1

\begin{tabular}{|c|c|c|c|c|}
\hline \multirow{2}{*}{ Variable } & \multirow{2}{*}{ HR } & \multicolumn{2}{|c|}{$95 \%$ CI } & \multirow{2}{*}{$p$ Value } \\
\hline & & Lower & Upper & \\
\hline Others & \multicolumn{4}{|c|}{ Ref. } \\
\hline SATB1 $^{\text {low }}$ SMAD $3^{\text {high }} \mathrm{EZR}^{\text {high }} \mathrm{CTNNB} 1^{\text {high }}$ & 2.97 & 1.863 & 4.745 & $<0.0001$ \\
\hline 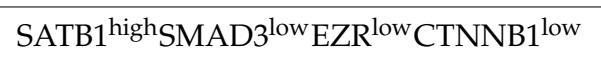 & 0.35 & 0.084 & 1.420 & 0.14 \\
\hline
\end{tabular}

Significant $p$ values $(p<0.05)$ are marked in bold. Abbreviations: CI, confidence interval; HR hazard ratio; TCGA-The Cancer Genome Atlas. (A) Univariate analysis of own cohort: SATB1 ${ }^{\mathrm{n}} /$ SMAD3/Ezrin/ $\beta$-catenin:SATB1 ${ }^{\text {-high }} S_{M A D} 3^{\text {low }}$ Ezrin $^{\text {low }} \beta$-catenin ${ }^{\text {low }}(n=5)$; SATB1 ${ }^{\text {n-low }}$ SMAD $^{\text {high }}$ Ezrin $^{\text {high }} \beta$ catenin $^{\text {high }}(n=9)$; Others $(n=54)$. (B) Univariate analysis of own cohort: SATB1 $/$ SMAD3/Ezrin $/ \beta$ catenin:SATB1 ${ }^{\text {c-present }}$ SMAD $3^{\text {high }}$ Ezrin $^{\text {high }} \beta$-catenin high $(n=6) ;$ SATB1 $^{\text {c-absent }}$ SMAD ${ }^{\text {low }}$ Ezrin $^{\text {low }} \beta$-catenin ${ }^{\text {low }}$ $(n=8)$; Others $(n=54)$. (C) Univariate analysis of TCGA cohort: SATB1/SMAD3/EZR/CTNNB1:SATB1 ${ }^{\text {low }}$ $\mathrm{SMAD}^{\text {high }} \mathrm{EZR}^{\text {high }} \mathrm{CTNNB} 1^{\text {high }}(n=32)$; SATB1 ${ }^{\text {high }} \mathrm{SMAD}^{\text {low }} \mathrm{EZR}^{\text {low }} \mathrm{CTNNB} 1^{\text {low }}(n=12)$; Others $(n=133)$.

Survival analysis of the TCGA cohort showed that SATB1/SMAD3/EZR/CTNNB1 expression panel was strongly associated with OS (381 days vs. undefined, $p<0.0001$; Figure $6 \mathrm{C}$ ). The univariate analysis demonstrated that SATB $1^{\text {low }}$ SMAD $3{ }^{\text {high }} E Z R^{\text {high }} C T N N B 1^{\text {high }}$ expression was significantly associated with a worse survival prognosis (HR 2.97, 95\% CI 1.86-4.76, $p<0.0001$; Table 7C), and it persisted as an independent prognostic factor for poorer OS in the multivariate analysis (HR 3.28, 95\% CI 2.02-5.33, $p<0.0001$; Table 8C).

Table 8. Multivariate analysis of prognostic factors by the Cox proportional hazard model for combined expression.

\begin{tabular}{|c|c|c|c|c|}
\hline \multicolumn{5}{|c|}{ (A) Multivariate Analysis of Own Cohort: SATB1 ${ }^{\text {n}} /$ SMAD3/Ezrin/ $\beta$-Catenin } \\
\hline \multirow{2}{*}{ Variable } & \multirow{2}{*}{ HR } & \multicolumn{2}{|c|}{$95 \% \mathrm{CI}$} & \multirow{2}{*}{$p$ Value } \\
\hline & & Lower & Upper & \\
\hline Others & \multicolumn{4}{|c|}{ Ref. } \\
\hline SATB1 ${ }^{\text {n-high }}$ SMAD $3^{\text {low }}$ Ezrin ${ }^{\text {low }} \beta$-catenin ${ }^{\text {low }}$ & 0.11 & 0.01 & 0.93 & 0.04 \\
\hline SATB1 $^{\text {n-low }}{ }^{\text {SMAD }}{ }^{\text {high }}$ Ezrin $^{\text {high }} \beta$-catenin ${ }^{\text {high }}$ & 2.91 & 1.07 & 7.91 & 0.04 \\
\hline age & 1.06 & 1.02 & 1.11 & 0.005 \\
\hline TNM stage & 1.67 & 0.77 & 3.62 & 0.19 \\
\hline LVI & 3.81 & 1.85 & 7.83 & $<0.0001$ \\
\hline \multicolumn{5}{|c|}{ (B) Multivariate Analysis of Own Cohort:SATB1 ${ }^{\mathrm{C}} / \mathrm{SMAD3} /$ Ezrin/ $\beta$-catenin } \\
\hline \multirow{2}{*}{ Variable } & \multirow{2}{*}{ HR } & \multicolumn{2}{|c|}{$95 \% \mathrm{CI}$} & \multirow{2}{*}{$p$ Value } \\
\hline & & Lower & Upper & \\
\hline Others & \multicolumn{4}{|c|}{ Ref. } \\
\hline SATB1 ${ }^{\text {c-present }}$ SMAD $3^{\text {high }}$ Ezrin $^{\text {high }} \beta$-catenin high & 7.32 & 2.05 & 26.21 & 0.002 \\
\hline SATB1 $^{\text {c-absent }}$ SMAD3 ${ }^{\text {low }}$ Ezrin $^{\text {low }} \beta$-catenin ${ }^{\text {low }}$ & 0.09 & 0.02 & 0.46 & 0.003 \\
\hline age & 1.07 & 1.03 & 1.12 & 0.001 \\
\hline TNM stage & 3.08 & 1.49 & 6.36 & 0.002 \\
\hline LVI & 2.68 & 1.37 & 5.25 & 0.004 \\
\hline
\end{tabular}


Table 8. Cont.

(C) Multivariate Analysis of TCGA Cohort: SATB1/SMAD3/EZR/CTNNB1

\begin{tabular}{|c|c|c|c|c|}
\hline \multirow{2}{*}{ Variable } & \multirow{2}{*}{ HR } & \multicolumn{2}{|c|}{$95 \%$ CI } & \multirow{2}{*}{$p$ Value } \\
\hline & & Lower & Upper & \\
\hline Others & \multicolumn{4}{|c|}{ Ref. } \\
\hline SATB1 $^{\text {low }}$ SMAD $3^{\text {high }} \mathrm{EZR}^{\text {high }} \mathrm{CTNNB} 1^{\text {high }}$ & 3.28 & 2.02 & 5.33 & $<0.0001$ \\
\hline SATB1 $1^{\text {high }}$ SMAD3 $3^{\text {low }} \mathrm{EZR}^{\text {low }} \mathrm{CTNNB} 1^{\text {low }}$ & 0.57 & 0.14 & 2.35 & 0.44 \\
\hline age & 1.02 & 1.00 & 1.05 & 0.01 \\
\hline grade & 1.57 & 0.83 & 2.98 & 0.17 \\
\hline $\mathrm{pN}$ & 2.24 & 1.27 & 3.95 & 0.01 \\
\hline $\mathrm{pT}$ & 1.28 & 0.61 & 2.66 & 0.51 \\
\hline
\end{tabular}

Significant $p$ values $(p<0.05)$ are marked in bold. Abbreviations: $\mathrm{CI}$, confidence interval; HR, hazard ratio LVI—vascular invasion. HR: adjusting for age, TNM stage, VI. HR from TCGA: adjusting for age, grade, $\mathrm{pN}$, pT. (A) Multivariate analysis of own cohort: SATB1 ${ }^{\mathrm{n}} / \mathrm{SMAD} 3 /$ Ezrin $/ \beta$-catenin:SATB1 ${ }^{\text {n-high }}$ SMAD ${ }^{\text {low }}$ Ezrin $^{\text {low }} \beta$ catenin $^{\text {low }}(n=5)$; SATB1 ${ }^{\text {n-low }}$ SMAD3 ${ }^{\text {high }}$ Ezrin $^{\text {high }} \beta$-catenin ${ }^{\text {high }}(n=9)$; Others $(n=54)$. (B) Multivariate analysis of own cohort: SATB1 ${ }^{\mathrm{c}} / \mathrm{SMAD} 3 /$ Ezrin $/ \beta$-catenin:SATB1 ${ }^{\text {c-present }}$ SMAD $3^{\text {high }}$ Ezrin $^{\text {high }} \beta$-catenin ${ }^{\text {high }}$ $(n=6)$; SATB1 $1^{\text {c-absent }}$ SMAD $3^{\text {low }}$ Ezrin $^{\text {low }} \beta$-catenin ${ }^{\text {low }}(n=8)$; Others $(n=54) . \quad(C)$ Multivariate analysis of TCGA cohort: SATB1/SMAD3/EZR/CTNNB1: SATB1 ${ }^{\text {low }}$ SMAD3 ${ }^{\text {high }}$ EZR $^{\text {high }}$ CTNNB1 ${ }^{\text {high }}(n=32)$; SATB1 ${ }^{\text {high }}$ SMAD $3^{\text {low }}$ EZR $^{\text {low }}$ CTNNB1 $1^{\text {low }}(n=12)$; Others $(n=133)$.

\subsection{PPI Network Constructionand Functional Enrichment Analysis}

To better understand the biological relationship of $\beta$-catenin, Ezrin, SATB1 and SMAD3, the PPI network consisting of seed proteins and their interaction partners was constructed using the STRING online database and Cytoscape software (Figure 7A). There were 54 nodes and 538 edges in the PPI network (PPI enrichment $p$ value $<1.0 \times 10^{-16}$; local clustering coefficient 0.69 ). Further details on the network parameters were obtained by the Cytoscape plugin Network Analyzer, and these are presented in Supplementary data (Table S3). The 10 hub genes were then determined based on the degree score of the nodes in the network using the Cytoscape plugin cytoHubba (Figure 7A; colored nodes). Next, the top two cluster subnetworks were identified from the PPI network with the help of the MCODE plugin (cluster 1: 25 nodes, 236 edges, cluster score: 19.67 (Figure 7B); cluster 2:10 nodes, 18 edges, cluster score: 4.0 (Figure 7C)).

Furthermore, the Reactome Pathway, KEGG Pathway, GO and KEGG Brite enrichment analyses were performed to predict signaling pathways, gene ontological features and functional hierarchies of CTNNB1, EZR, SATB1, SMAD3 and their 50 interaction partners. The Reactome Pathway hierarchy panel is illustrated in Figure 8A. This analysis showed that the queried genes and their neighbors were mainly involved in signaling by $\mathrm{WNT} / \beta-$ catenin, diseases of signal transduction by growth factor receptors and second messengers, transcription and signal transduction (Figure 8B). KEGG pathway analysis demonstrated that the imputed genes were highly associated with adherens junction, endometrial cancer, WNT signaling pathway, Hippo signaling pathway and pathways in cancer (Figure 9A). KEGG BRITE functional hierarchies revealed that there was a preponderance of genes representing transcription factors, chromosome and associated proteins, enzymes and cytoskeleton proteins (Figure 9B). In GO analysis, the most enriched ontology terms were canonical WNT signaling pathway (Figure 9C), cell-cell adherens junction (Figure 9D) and $\beta$-catenin binding (Figure 9E). 

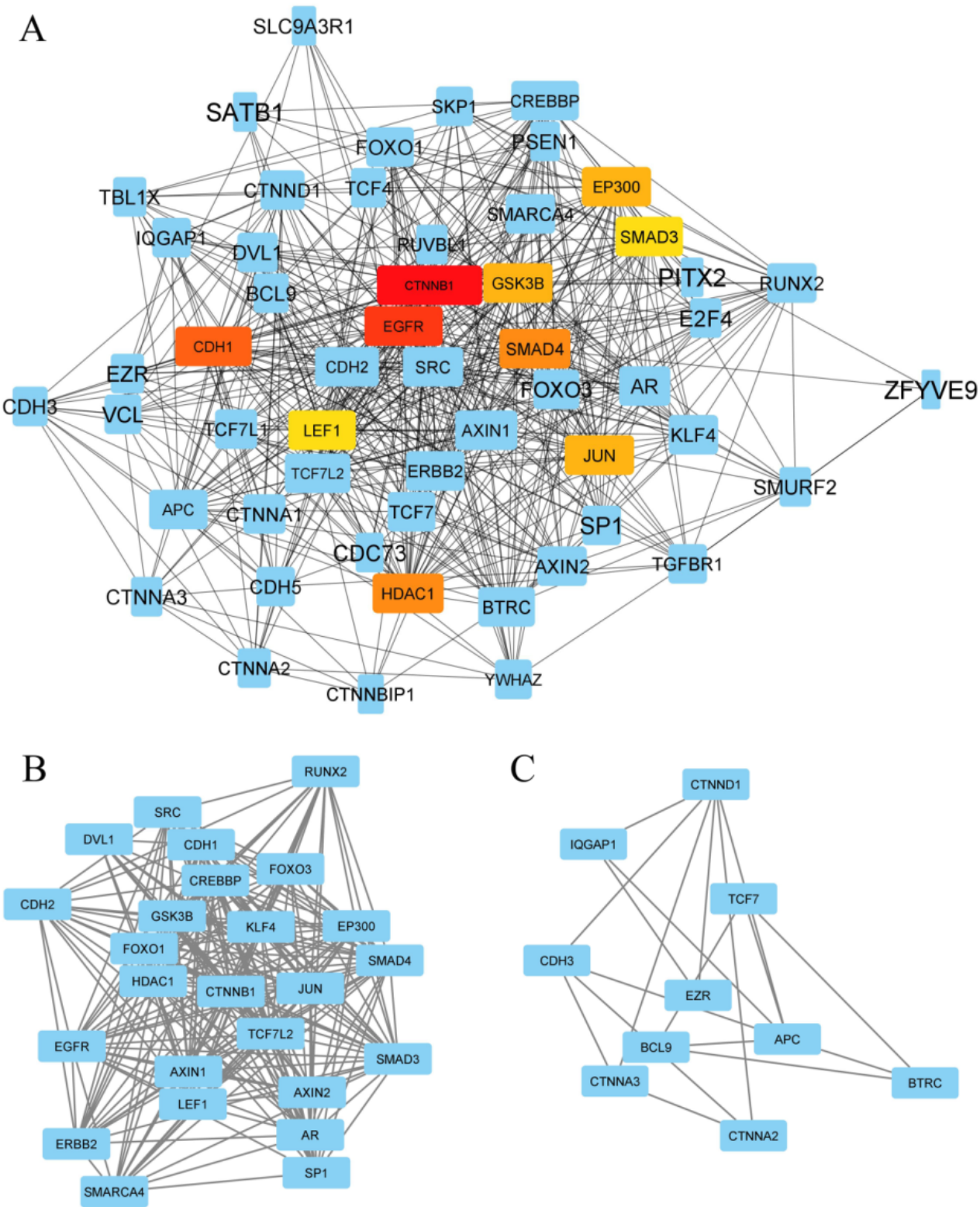

Figure 7. Protein-protein interaction network for $\beta$-catenin, Ezrin, SATB1, SMAD3 and their 50 neighbors. PPI network properties, such as node degree and clustering coefficient, are visualized by shape size and label font size, respectively. Top 10 hub genes in the network identified by the CytoHubba Cytoscape plugin are highlighted in a red to yellow gradient. The deeper color, the higher degree of enrichment. Other nodes in the network are highlighted in blue (A). The MCODE clustering algorithm was used to identify the clusters in the PPI network. The top two clusters identified by MCODE are displayed $(\mathbf{B}, \mathbf{C})$. 


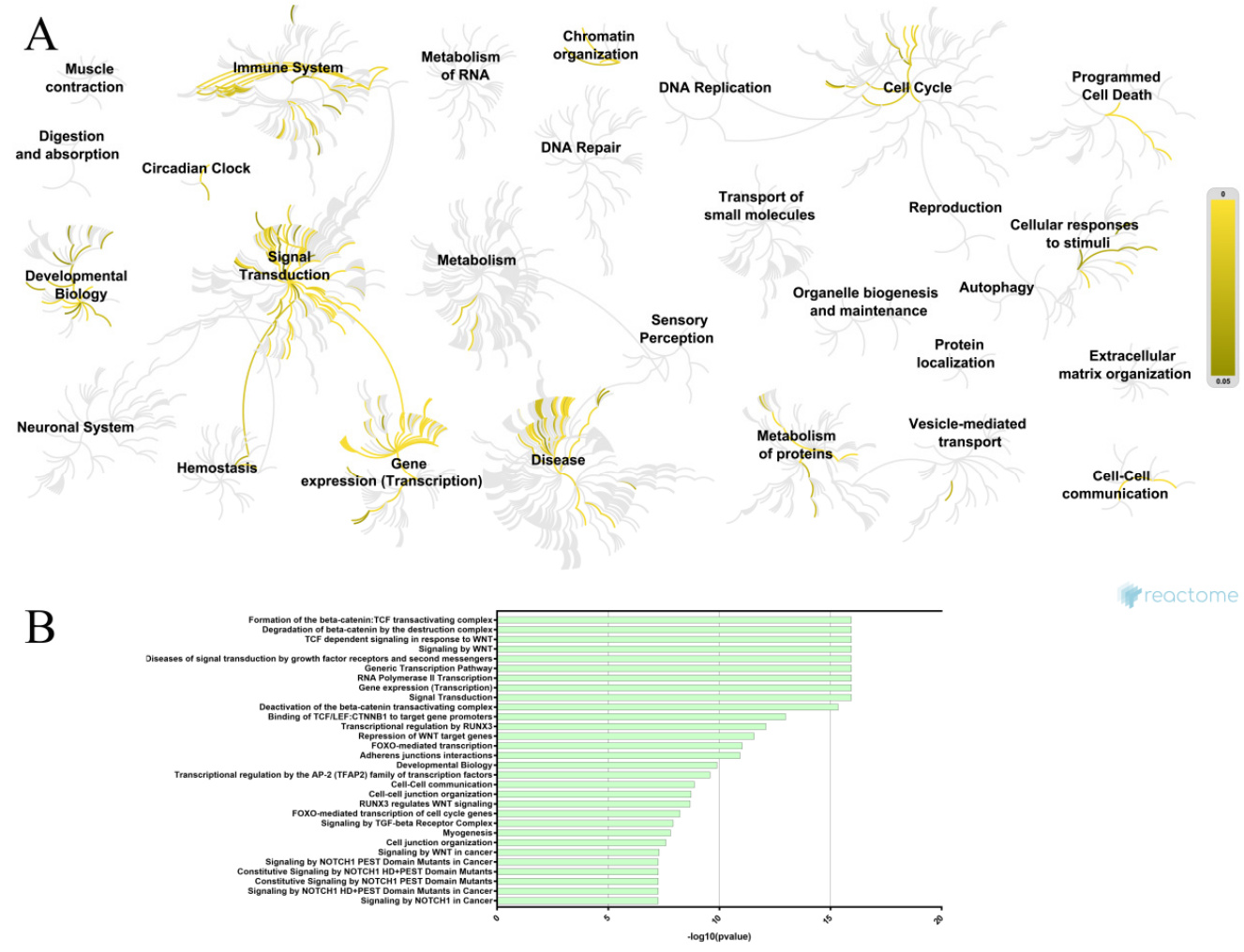

Figure 8. Reactome Pathway functional enrichment analysis for CTNNB1, EZR, SATB1, SMAD3 and their 50 interaction partners. (A) Reactome Pathway hierarchy panel; (B) Top 30 Reactome pathways. The $p$ value was calculated and sorted with $-\log 10$ ( $p$ value).

A
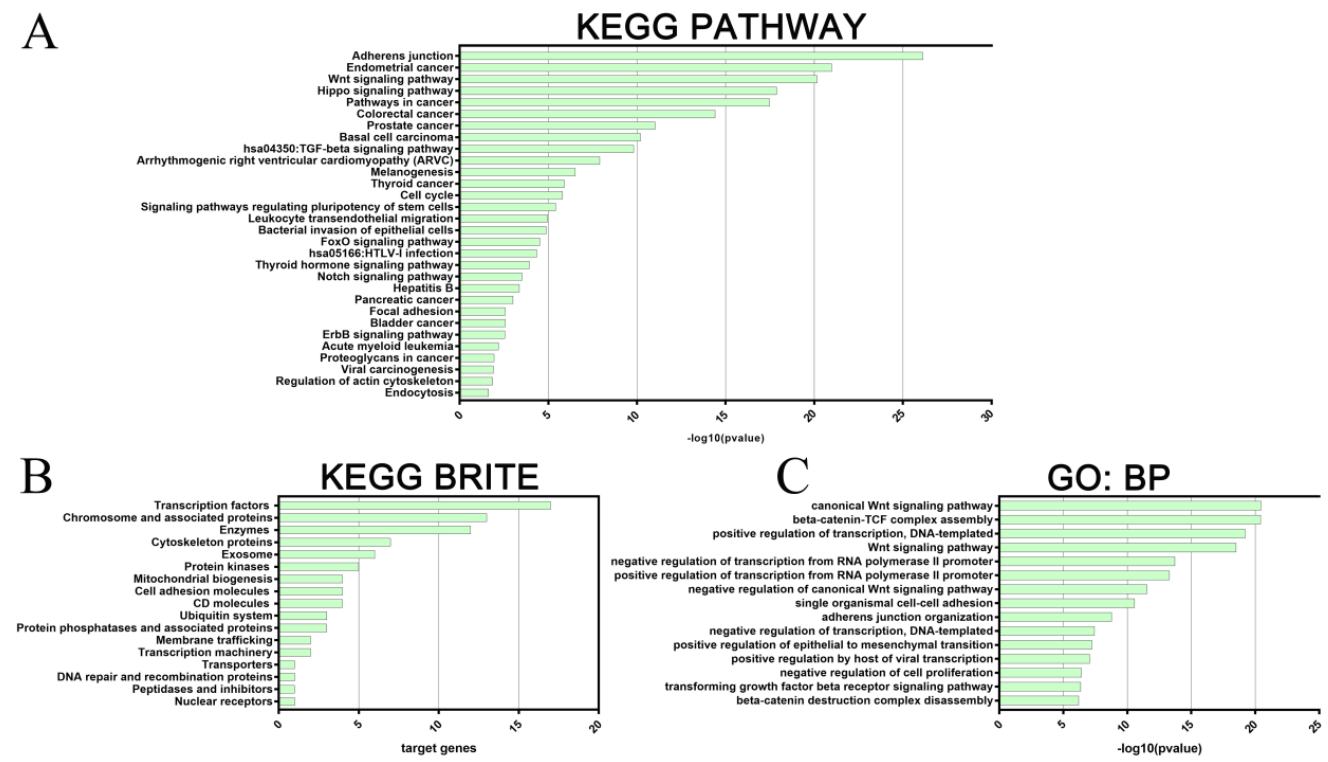

D
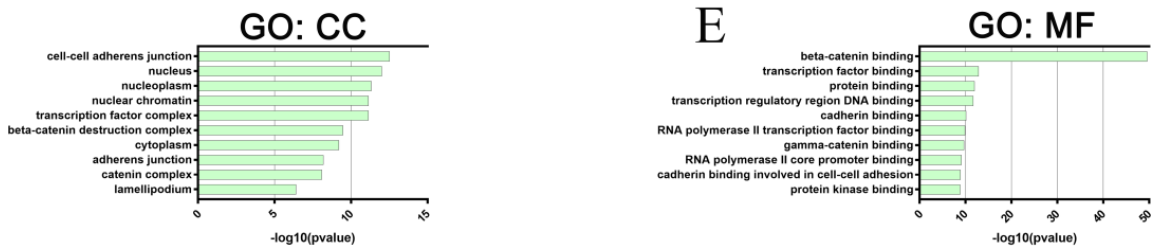

Figure 9. KEGG Pathway, KEGG Brite and GO functional enrichment analysis for CTNNB1, EZR, SATB1, SMAD3 and their 50 interaction partners. (A) Top 15 terms in KEGG pathway analysis; 
(B) all terms in KEGG Brite analysis; (C) Top 15 terms in biological processes (BP) category; (D) Top 10 terms incellular components (CC) category; (E) Top 10 terms in molecular functions (MF) category. The $p$ value was calculated and sorted with $-\log 10$ ( $p$ value).

\section{Discussion}

In this study, we investigated the associations between the expression status of SATB1, SMAD3, Ezrin, $\beta$-catenin and clinicopathological variables, including survival outcome of PDAC patients. Importantly, we evaluated the utility of the examined factors as prognostic markers in pancreatic cancer separately and in combination. To verify the results, we complemented the protein expression data of our cohort with mRNA-seq data of PAC cases obtained from the TCGA. In addition, the protein-protein interaction (PPI) network for $\beta$-catenin, Ezrin, SATB1, SMAD3 and their 50 neighbors was constructed and functionally annotated.

In the past few years, several studies have been conducted to evaluate the expression level and role of SATB1 in many human cancers, including PDAC [32-34]. In our investigation, expression of SATB1 ${ }^{\mathrm{n}}$ was significantly reduced or lost in PDAC specimens as compared to non-cancerous adjacent tissues, while SATB1 ${ }^{\mathrm{C}}$ was present in the abnormal tissue, but it was not observed in any of the control samples. Guo et al. revealed that SATB1 expression was significantly upregulated in pancreatic cancer specimens compared to in non-cancerous adjacent tissues [32]. However, Guo et al. did not specify what type of SATB1 immunoexpression patterns they assessed, but on the representative micrograph of pancreatic cancer tissue, exclusively cytoplasmic pattern could be seen [32]. Our finding suggests that cells of the pancreatic ducts undergo a significant loss of SATB1 $1^{\mathrm{n}}$ expression during pancreatic carcinogenesis, and this preferentially takes place in well-differentiated and moderately differentiated cancer cells than in the poorly differentiated ones. Notably, loss of SATB $1^{\mathrm{n}}$ expression in PDAC specimens was associated with reduced OS (297 days vs. 561 days), but the survival difference was not statistically significant $(p=0.118)$. On the other hand, SATB $1^{\mathrm{C}}$ was only present in PDAC (30.88\%) but not in the control tissue, leading us to hypothesize that this staining pattern may have a clinical meaning in PDAC. Indeed, patients with $S A T B 1^{c}$ expression had significantly shorter median OS than patients without cytoplasmic SATB1 staining (458 vs. 117 days). Furthermore, in the multivariate analysis accounting for conventional risk factors, $\mathrm{SATB}^{\mathrm{c}}$ expression tended to be an independent prognostic factor for poor overall survival. Our study may be simply underpowered to observe statistically significant effects of SATB1 in our cohort because of the relatively small sample size and the limited number of samples overexpressing SATB1 ${ }^{\mathrm{n}}$ or those exhibiting cytoplasmic SATB1 staining. Nevertheless, without reaching statistical significance in certain survival analyses, our results do not allow us to infer anything conclusively on the role of SATB1 in PDAC. However, they still raise the possibility that SATB1 may function as a tumor suppressor in at least some PDAC cases, i.e., under specific clinicopathological circumstances. SATB1 functions as a nuclear DNA-binding protein, and herein, it was SATB1's inability to fulfill its nuclear roles due to the loss of nuclear expression and/or cytoplasmic retention that correlated with a poor prognosis of PDAC patients. It is not unexpected, given that SATB1 acts as a global epigenetic and transcriptional regulator of gene expression. Thus, loss of its function may lead to widespread genomic consequences that can contribute to cancer [35]. Furthermore, in our TCGA data, high expression levels of SATB1 mRNA were found to predict better OS independently of age at diagnosis, tumor grade, as well as $\mathrm{pT}$ and $\mathrm{pN}$ stage. As an aside, Nakayama et al. reported that cytoplasmic SATB1 localization in T cells could be attributed to a single point mutation at either Lys29 or Arg32, which abrogates its nuclear localization [36]. Whether this stays true in PDAC requires additional studies. Additionally, the fact that cytoplasmic SATB1 labeling was exclusively observed in cancer cells, but not in normal cells, which retained nuclear expression in the majority of cases (95.31\%), argues in favor of a potential tumor-suppressive function of SATB1 in PDAC. It is generally known that tumor suppressors possessing 
transcriptional functions tend to localize in the nucleus of normal cells but in the cytoplasm of cancer cells [37]. In the context of clinical utility, our study is suggestive of the opposite prognostic meaning for the cytoplasmic and nuclear SATB1 in pancreatic adenocarcinoma. However, this conclusion is hampered by the fact that, in our series, the association between high SATB1 ${ }^{\mathrm{n}}$ and improved OS did not reach statistical significance. More convincing evidence is therefore required to ascertain whether the clinical impact of SATB1 indeed corresponds to its subcellular distribution in PDAC. From all this, we can more confidently conclude that our research results recommend the individual analysis of cytoplasmic and nuclear SATB1 for a more precise prognostic prediction in pancreatic adenocarcinoma.

As far as we are aware, the present study is the first to distinguish the individual prognostic impact of cytoplasmic and nuclear SATB1 in PDAC. Previous studies, including our own [38], performed similar analyses in colorectal cancer [35,39] and non-small cell lung cancer [38]. We found that in our series of PDACs, the prognostic ability of cytoplasmic SATB1 in OS analysis was even superior to nuclear SATB1. In turn, nuclear SATB1 expression was evaluated by Elebro et al., who demonstrated its association with adverse prognosis in pancreatobiliary-type adenocarcinomas and its ability to predict responses to adjuvant treatment in both intestinal-type and pancreatobiliary-type periampullary adenocarcinomas, including pancreatic cancer [34]. Moreover, Chen et al. have shown that SATB1 expression is associated with pancreatic cancer invasion depth and tumor staging, which confirmed their in vitro results showing that SATB1 promotes pancreatic cancer proliferation and invasion [33]. Nevertheless, the authors, similar to Guo et al., did not specify what type of SATB1 immunoexpression patterns they evaluated, making the results hard to compare $[32,33]$. Undoubtedly interesting and complex, yet still inconsistent or contradictory picture of SATB1 emerges from pancreatic cancer studies. Therefore, SATB1's role in PDAC merits further examination in additional patient cohorts, as well as in a mechanistic context.

As demonstrated by Lv et al., SATB1 might promote the epithelial to mesenchymal transition by increasing the aberrant expression of $\beta$-catenin [40]. SATB1 has also been shown to interact with $\beta$-catenin and recruit it into its genomic binding sites, hence mediating Wnt/ $\beta$-catenin signaling in T-helper type 2 cells. Additionally, in our study, SATB1 expression was found to be correlated with that of $\beta$-catenin, both at protein and mRNA levels [41]. Notably, in our investigation, we observed that $\beta$-catenin expression in PDAC was membranous and cytoplasmic but without nuclear staining. In accordance with Wang et al., we found no association of cytoplasmic $\beta$-catenin expression with PDAC (Figure S2, Tables S4-S6); therefore, our results considered only membrane staining pattern [42]. Consistent with some previous studies, the membranous expression of $\beta$-catenin was significantly lower in PDAC than in adjacent normal tissue [43-45]. However, opposite findings have also been made in some other studies. Indeed, up-regulation of $\beta$-catenin in PDAC was presented by Wang et al., Zeng et al. and Magliano et al. [42,46,47]. These discrepancies are most probably due to different control tissues and evaluation of different staining patterns. In contrast to our cohort, CTNNB1 mRNA was significantly up-regulated in PAC tissues of the TCGA cohort compared with normal pancreatic tissues. At mRNA, but not protein level, high expression of CTNNB1 was associated with features of biological aggressiveness, including high grade, increased T stage and advanced TMN stage. Kaplan-Meier survival analysis of our dataset showed that there was a suggestive association between high $\beta$-catenin expression and shorter survival of PDAC patients ( $274 \mathrm{vs.}$ 450 days; $p=0.09$ ). In the TCGA cohort, this association was statistically significant (592 vs. 2182 days; $p=0.001)$. Nevertheless, neither protein nor mRNA expression of $\beta$-catenin was an independent prognostic factor when considering confounding factors, including age, tumor stage and LVI. Sano et al. showed that a high IHC score for $\beta$-catenin correlated with a poor prognosis, but the researchers evaluated nuclear expression in tissues from PDAC patients and did not perform th multivariate analysis [48]. The opposite relationship regarding $\beta$-catenin protein expression and patient survival was presented by Saukkonen et al., 
however, due to the difficulty in evaluating membrane and cytoplasm staining separately, the authors of the cited results assessed only cytoplasmic expression pattern [13].

In our investigation, we also found positive associations between the expression of $\beta$ catenin and SMAD3, both in our cohort and TCGA cohort. Furthermore, SMAD3 expression was significantly higher in PDAC specimens as compared to control tissues both at mRNA and protein levels, which is consistent with the report of Yamazaki et al. [49]. Furthermore, our analyses showed that patients with high SMAD3 expression had significantly lower median OS than did patients with SMAD3 underexpression ( 290 vs. 531 days). Importantly, further analysis using a Cox proportional hazard regression model revealed that SMAD3 expression was an independent prognostic factor predicting poorer survival in PDAC patients. Analysis of SMAD3 mRNA levels from the TCGA cohort confirmed these results. Similar findings regarding OS have been presented by Yamazaki et al. [49]. Moreover, they demonstrated that the expression of SMAD3 in PDAC correlated with malignant characteristics, including EMT-like features and lymph node metastasis. This is in partial agreement with our study since we observed a significant correlation of SMAD3 mRNA but not protein expression with the features of aggressive tumor behavior, such as higher grade, positive nodal status, higher pT category and TNM stage. These results confirm that SMAD3 expression may reflect the malignancy potential of PDAC and serve as a biomarker of a poor prognosis.

Spearman's analysis showed strong positive correlations between SMAD3 and EZR in the TCGA cohort. Recently, various studies demonstrated that Ezrin may play an important role in cancer progression, while its overexpression correlates with patient survival and various clinicopathological parameters [50-52]. According to our report, Ezrin expression was elevated in PDAC samples compared to adjacent tissues, which is consistent with the studies by other researchers $[50,52,53]$. Immunohistochemical analysis of our cohort showed that Ezrin protein expression did not correlate with clinicopathological parameters. However, EZR mRNA expression significantly correlated with aggressive phenotypes of PDACs from the TCGA cohort, including differentiation stage, pT status and TNM stage. Previous studies have shown elevated Ezrin protein expression correlated with tumor size, clinical stage and positive lymph node metastasis in PDAC [50]. Our Kaplan-Meier survival analysis demonstrated that high Ezrin expression correlated with a shorter OS rate than a low expression (118 vs. 450 days). Moreover, we revealed that elevated Ezrin expression in our cohort was an independent prognostic factor predicting poorer survival in PDAC patients. The effects of EZR expression on the survival of patients from our cohort and TCGA cohort are consistent. Similar findings have also been presented in the studies by other investigators; thus, we confirmed the role of EZR in the prognosis prediction of PDAC [50,51].

Furthermore, given the relationship between SATB1 and $\beta$-catenin [40], SATB1 and SMAD3 [54], $\beta$-catenin and SMAD3 [55], SMAD3 and Ezrin [56], we next evaluated whether there was any possible added value of combining SATB1, SMAD3, Ezrin and $\beta$-catenin to the prognostic value of each of the proteins alone. Kaplan-Meier survival analysis demonstrated that the subset of patients whose tumors co-expressed high levels of SATB1 ${ }^{\mathrm{C}}$, SMAD3, Ezrin and $\beta$-catenin had extremely poor OS, and the combined expression of these markers better predicted patient survival than looking at each marker individually. Moreover, this combined 4-protein panel proved to be a powerful independent prognostic factor associated with worse outcome. In turn, a particularly improved OS was experienced by patients with tumors expressing SATB1 ${ }^{\text {n-high }}$ SMAD $3^{\text {low }}$ Ezrin $^{\text {low }} \beta$-catenin ${ }^{\text {low }}$, and this expression panel appeared as an independent positive prognostic factor in the multivariate Cox analysis.

Likewise, in the TCGA dataset, a combined 4-gene panel of SATB1/SMAD3/EZR/CTNNB1 better predicted patient survival than looking at each marker individually, and it emerged as a powerful independent prognostic factor associated with poorer patient outcomes. Thus, our analyses showed that examining the combined expression of SATB1, SMAD3, Ezrin and $\beta$-catenin may be more helpful in predicting the prognosis of PAC patients than single 
markers. This could be because the predicted biology related to their co-expression included significant interconnectivity with certain master regulators associated with cancer phenotype, as shown by our functional enrichment analysis. Likewise, the biological processes and signaling pathways that emerged from the PPI network are known or are suspected to have a tight cause-and-effect relationship with carcinogenesis. However, the answer to whether these are implicated in the mechanisms linking SATB1/SMAD3/Ezrin/ $\beta$-catenin co-expression to PDAC will require further study.

As a major limitation, we want to emphasize that the small cohort size may hamper the statistical power of our study. Specifically, when we focused the subsequent analyses on the combined expression of the studied proteins, the sample size in certain subgroups became relatively small, but the number of cases was still within the range accepted in other studies $[57,58]$. Nevertheless, our findings should be validated with a larger sample size. It is appreciated that a more robust multivariate analysis should include at least 10 events per variable.

\section{Conclusions}

In conclusion, protein and/or mRNA expression levels of SATB1, SMAD3, Ezrin and $\beta$ catenin are significantly altered in PAC and may correlate with some tumor features as well as provide prognostic information as single indicators, and even better when combined.

Supplementary Materials: The following are available online at https:/ / www.mdpi.com/article/10 .3390 /app12010306/s1, Figure S1. Kaplan-Meier curve for overall survival in patients with pancreatic ductal adenocarcinomas by nuclear/cytoplasmic SATB1 protein expression. $p$ value was calculated using the log-rank test. Figure S2. Kaplan-Meier curve for overall survival in patients with pancreatic ductal adenocarcinomas by cytoplasmic $\beta$-catenin protein expression. $p$ value was calculated using the log-rank test. Table S1. Univariate analysis of prognostic factors by Cox proportional hazard model in own cohort for cytoplasmic $\beta$-catenin protein expression. Table S2. Multivariate analysis of prognostic factors by Cox proportional hazard model in own cohort for cytoplasmic $\beta$-catenin protein expression. Table S3. Parameters of network determined using the network analyzer Cytoscape plugin. Table S4. Immunohistochemical expression of cytoplasmic $\beta$-catenin proteins and their relationship with clinicopathological features of PDAC patients. Table S5. Univariate analysis of prognostic factors by Cox proportional hazard model in own cohort for cytoplasmic $\beta$-catenin protein expression. Table S6. Multivariate analysis of prognostic factors by Cox proportional hazard model in own cohort for cytoplasmic $\beta$-catenin protein expression.

Author Contributions: Conceptualization: D.G., J.D. and A.K.-W.; data curation: J.D., A.K.-W., P.A. and A.G.; formal analysis: J.D., A.K.-W., P.C. and K.M.; funding acquisition: A.K.-W.; investigation: J.D.; methodology: J.D. and P.A.; project administration: A.K.-W.; staining evaluation: E.D. and N.S.-M.; supervision: A.K.-W. and D.G.; writing—original draft: J.D., A.K.-W. and W.Z.; writingreview and editing: D.G. and A.K.-W. All authors have read and agreed to the published version of the manuscript.

Funding: This research was funded by Nicolaus Copernicus University in Torun, Faculty of Medicine, Collegium Medicum in Bydgoszcz, research task no. MN-1/WL/2019.

Institutional Review Board Statement: This study was conducted according to the guidelines of the Declaration of Helsinki and approved by the Institutional Ethics Committee of Nicolaus Copernicus University in Torun, Collegium Medicum in Bydgoszcz (KB 342/2020; 23 June 2020).

Informed Consent Statement: Patient consent was waived due to the retrospective nature of the study. The requirement for informed consent was waived by the Institutional Ethics Committee of Nicolaus Copernicus University in Torun, Collegium Medicum in Bydgoszcz.

Data Availability Statement: Publicly available datasets were analyzed in this study. These data can be found here: http:/ / www.cbioportal.org/study / summary?id=paad_tcga_pan_can_atlas_2018 (accessed on 3 July 2020); https: / / xenabrowser.net (accessed on 3 July 2021). Our own data presented in this study are available on request from the corresponding author. The data are not publicly available due to ethical restrictions. 
Conflicts of Interest: The authors declare no conflict of interest.

\section{References}

1. Sung, H.; Ferlay, J.; Siegel, R.L.; Laversanne, M.; Soerjomataram, I.; Jemal, A.; Bray, F. Global cancer statistics 2020: GLOBOCAN estimates of incidence and mortality worldwide for 36 cancers in 185 countries. CA Cancer J. Clin. 2021, 71, 209-249. [CrossRef]

2. Siegel, R.L.; Miller, K.D.; Jemal, A. Cancer statistics, 2017. CA Cancer J. Clin. 2017, 67, 7-30. [CrossRef] [PubMed]

3. Rawla, P.; Sunkara, T.; Gaduputi, V. Epidemiology of Pancreatic Cancer: Global Trends, Etiology and Risk Factors. World J. Oncol. 2019, 10, 10-27. [CrossRef] [PubMed]

4. Kong, J.; Di, C.; Piao, J.; Sun, J.; Han, L.; Chen, L.; Yan, G.; Lin, Z. Ezrin contributes to cervical cancer progression through induction of epithelial-mesenchymal transition. Oncotarget 2016, 7, 19631-19642. [CrossRef] [PubMed]

5. Zhong, Z.Q.; Song, M.M.; He, Y.; Cheng, S.; Yuan, H.S. Knockdown of Ezrin by RNA interference reverses malignant behavior of human pancreatic cancer cells in vitro. Asian Pacific J. Cancer Prev. 2012, 13, 3781-3789. [CrossRef]

6. Quan, C.; Yan, Y.; Qin, Z.; Lin, Z.; Quan, T. Ezrin regulates skin fibroblast size/mechanical properties and YAP-dependent proliferation. J. Cell Commun. Signal 2018, 12, 549-560. [CrossRef]

7. Kretzschmar, M.; Doody, J.; Massagué, J. Opposing BMP and EGF signalling pathways converge on the TGF- $\beta$ family mediator Smad1. Nature 1997, 389, 618-622. [CrossRef]

8. Kang, Y.; Siegel, P.M.; Shu, W.; Drobnjak, M.; Kakonen, S.M.; Cordón-Cardo, C.; Guise, T.A.; Massagué, J. A multigenic program mediating breast cancer metastasis to bone. Cancer Cell 2003, 3, 537-549. [CrossRef]

9. Kang, Y.; He, W.; Tulley, S.; Gupta, G.P.; Serganova, I.; Chen, C.R.; Manova-Todorova, K.; Blasberg, R.; Gerald, W.L.; Massagué, J. Breast cancer bone metastasis mediated by the Smad tumor suppressor pathway. Proc. Natl. Acad. Sci. USA 2005, 102, 13909-13914. [CrossRef]

10. Kim, Y.; Jin, D.; Lee, B.; Bin, C.; Han, J.; Shim, Y.M.; Kim, H.K.; Kim, D.H. Overexpression of $\beta$-Catenin and Cyclin D1 is Associated with Poor Overall Survival in Patients with Stage IA-IIA Squamous Cell Lung Cancer Irrespective of Adjuvant Chemotherapy. J. Thorac. Oncol. 2016, 11, 2193-2201. [CrossRef]

11. Melnik, S.; Dvornikov, D.; Müller-Decker, K.; Depner, S.; Stannek, P.; Meister, M.; Warth, A.; Thomas, M.; Muley, T.; Risch, A.; et al. Cancer cell specific inhibition of Wnt/ $\beta$-catenin signaling by forced intracellular acidification. Cell Discov. 2018, 4, 37. [CrossRef] [PubMed]

12. Deng, J.; Miller, S.A.; Wang, H.Y.; Xia, W.; Wen, Y.; Zhou, B.P.; Li, Y.; Lin, S.Y.; Hung, M.C. $\beta$-catenin interacts with and inhibits NF-KB in human colon and breast cancer. Cancer Cell 2002, 2, 323-334. [CrossRef]

13. Saukkonen, K.; Hagström, J.; Mustonen, H.; Juuti, A.; Nordling, S.; Kallio, P.; Alitalo, K.; Seppänen, H.; Haglund, C. PROX1 and $\beta$-catenin are prognostic markers in pancreatic ductal adenocarcinoma. BMC Cancer 2016, 16, 1-12. [CrossRef]

14. Linnemann, A.K.; Krawetz, S.A. Maintenance of a functional higher order chromatin structure: The role of the nuclear matrix in normal and disease states. Gene Ther. Mol. Biol. 2009, 13, 231-243.

15. Gottimukkala, K.P.; Jangid, R.; Patta, I.; Sultana, D.A.; Sharma, A.; Misra-Sen, J.; Galande, S. Regulation of SATB1 during thymocyte development by TCR signaling. Mol. Immunol. 2016, 77, 34-43. [CrossRef]

16. Grzanka, D.; Izdebska, M.; Klimaszewska-Wisniewska, A.; Gagat, M. The alterations in SATB1 and nuclear F-actin expression affect apoptotic response of the MCF-7 cells to geldanamycin. Folia Histochem. Cytobiol. 2015, 53, 79-87. [CrossRef]

17. Grzanka, D.; Gagat, M.; Izdebska, M. Involvement of the SATB1/F-actin complex in chromatin reorganization during active cell death. Int. J. Mol. Med. 2014, 33, 1441-1450. [CrossRef]

18. Han, H.J.; Russo, J.; Kohwi, Y.; Kohwi-Shigematsu, T. SATB1 reprogrammes gene expression to promote breast tumour growth and metastasis. Nature 2008, 452, 187-193. [CrossRef]

19. Nodin, B.; Johannesson, H.; Wangefjord, S.; O'Connor, D.P.; Lindquist, K.E.; Uhlén, M.; Jirström, K.; Eberhard, J. Molecular correlates and prognostic significance of SATB1 expression in colorectal cancer. Diagn. Pathol. 2012, 7, 115. [CrossRef]

20. Shukla, S.; Sharma, H.; Abbas, A.; MacLennan, G.T.; Fu, P.; Danielpour, D.; Gupta, S. Upregulation of SATB1 Is Associated with Prostate Cancer Aggressiveness and Disease Progression. PLoS ONE 2013, 8, e53527. [CrossRef]

21. Han, B.; Luan, L.; Xu, Z.; Wu, B. Expression and biological roles of SATB1 in human bladder cancer. Tumour Biol. 2013, 34, 2943-2949. [CrossRef]

22. Zheng, J. Is SATB1 a master regulator in breast cancer growth and metastasis? Womens Health 2008, 4, 329-332. [CrossRef]

23. Deng, Y.F.; Zhou, D.N.; Pan, Z.Y.; Yin, P. Aberrant SATB1 expression is associated with Epstein-Barr virus infection, metastasis and survival in human nasopharyngeal cells and endemic nasopharyngeal carcinoma. Int. J. Clin. Exp. Pathol. $2014,7,2454-2461$.

24. Chu, S.H.; Ma, Y.; Bin, F.; Zhang, H.; Zhu, Z.A.; Li, Z.Q.; Jiang, P.C. Upregulation of SATB1 is associated with the development and progression of glioma. J. Transl. Med. 2012, 10, 149. [CrossRef]

25. Klimaszewska-Wiśniewska, A.; Buchholz, K.; Neska-Długosz, I.; Sopo, P.; Grzanka, A.; Durślewicz, J.; Grzanka, D.; Zabrzy, J. RRM2 and SPDL1 and Their Prognostic Significance in Pancreatic Adenocarcinoma. Cancers 2021, 13, 859. [CrossRef]

26. Ogłuszka, M.; Orzechowska, M.; Jedroszka, D.; Witas, P.; Bednarek, A.K. Evaluate Cutpoints: Adaptable continuous data distribution system for determining survival in Kaplan-Meier estimator. Comput. Methods Programs Biomed. 2019, 177, 133-139. [CrossRef] 
27. Shannon, P.; Markiel, A.; Ozier, O.; Baliga, N.S.; Wang, J.T.; Ramage, D.; Amin, N.; Schwikowski, B.; Ideker, T. Cytoscape: A Software Environment for Integrated Models of Biomolecular Interaction Networks. Nucleic Acids Res. 2003, 13, $2498-2504$. [CrossRef]

28. Hu, L.; Zhao, T.; Sun, Y.; Chen, Y.; Bai, K.; Xu, F. Bioinformatic identification of hub genes and key pathways in neutrophils of patients with acute respiratory distress syndrome. Medicine 2020, 99, e19820. [CrossRef]

29. Jassal, B.; Matthews, L.; Viteri, G.; Gong, C.; Lorente, P.; Fabregat, A.; Sidiropoulos, K.; Cook, J.; Gillespie, M.; Haw, R.; et al. The reactome pathway knowledgebase. Nucleic Acids Res. 2020, 48, D498. [CrossRef]

30. Huang, D.W.; Sherman, B.T.; Lempicki, R.A. Systematic and integrative analysis of large gene lists using DAVID bioinformatics resources. Nat. Protoc. 2008, 4, 44-57. [CrossRef]

31. Kanehisa, M.; Goto, S.; Sato, Y.; Furumichi, M.; Tanabe, M. KEGG for integration and interpretation of large-scale molecular data sets. Nucleic Acids Res. 2012, 40, D109. [CrossRef]

32. Guo, L.; Zheng, J.; Yu, T.; Liu, Y.; Duo, L. Elevated expression of SATB1 is involved in pancreatic tumorigenesis and is associated with poor patient survival. Mol. Med. Rep. 2017, 16, 8842-8848. [CrossRef]

33. Chen, Z.; Li, Z.; Li, W.; Zong, Y.; Zhu, Y.; Miao, Y.; Xu, Z. SATB1 Promotes Pancreatic Cancer Growth and Invasion Depending on MYC Activation. Dig. Dis. Sci. 2015, 60, 3304-3317. [CrossRef]

34. Elebro, J.; Heby, M.; Gaber, A.; Nodin, B.; Jonsson, L.; Fristedt, R.; Uhlén, M.; Jirström, K.; Eberhard, J. Prognostic and treatment predictive significance of SATB1 and SATB2 expression in pancreatic and periampullary adenocarcinoma. J. Transl. Med. 2014, 12, 1-15. [CrossRef]

35. Al-Sohaily, S.; Henderson, C.; Selinger, C.; Pangon, L.; Segelov, E.; Kohonen-Corish, M.R.J.; Warusavitarne, J. Loss of special AT-rich sequence-binding protein 1 (SATB1) predicts poor survival in patients with colorectal cancer. Histopathology. 2014, 65, 155-163. [CrossRef]

36. Nakayama, Y.; Mian, I.S.; Kohwi-Shigematsu, T.; Ogawa, T. A nuclear targeting determinant for SATB1, a genome organizer in the T cell lineage. Cell Cycle. 2005, 4, 4099-4106. [CrossRef]

37. Wang, X.; Li, S. Protein mislocalization: Mechanisms, functions and clinical applications in cancer. Biochim. Biophys. Acta. 2014 1846, 13. [CrossRef]

38. Durślewicz, J.; Klimaszewska-Wiśniewska, A.; Jóźwicki, J.; Antosik, P.; Smolińska-Świtała, M.; Gagat, M.; Kowalewski, A.; Dariusz Grzanka, D. Prognostic significance of TLR2, SMAD3 and localizationdependent SATB1 in stage I and II non-small cell lung cancer patients. Cancer Control. 2021, 28, 1-14. [CrossRef]

39. Kowalczyk, A.E.; Godlewski, J.; Krazinski, B.E.; Kiewisz, J.; Sliwinska-Jewsiewicka, A.; Kwiatkowski, P.; Pula, B.; Dziegiel, P.; Janiszewski, J.; Wierzbicki, P.M.; et al. Divergent expression patterns of SATB1 mRNA and SATB1 protein in colorectal cancer and normal tissues. Tumor Biol. 2015, 36, 4441-4452. [CrossRef]

40. Lv, J.H.; Wang, F.; Yanfen, W.; Shen, M.H.; Wang, X.; Zhou, X.J. SATB1 expression is correlated with $\beta$-catenin associated epithelial-mesenchymal transition in colorectal cancer. Cancer Biol. Ther. 2016, 17, 254-261. [CrossRef]

41. Notani, D.; Gottimukkala, K.P.; Jayani, R.S.; Limaye, A.S.; Damle, M.V.; Mehta, S.; Purbey, P.K.; Joseph, J.; Galande, S. Global Regulator SATB1 Recruits $\beta$-Catenin and Regulates TH2 Differentiation in Wnt-Dependent Manner. PLoS Biol. 2010, 8, e1000296. [CrossRef] [PubMed]

42. Wang, Z.; Ma, Q.; Li, P.; Sha, H.; Li, X.; Xu, J. Aberrant Expression of CXCR4 and $\beta$-Catenin in Pancreatic Cancer. Anticancer Res. 2013, 4110, 4103-4110.

43. Qiao, Q.; Ramadani, M.; Gansauge, S.; Gansauge, F.; Leder, G.; Beger, H.G. Reduced membranous and ectopic cytoplasmic expression of beta -catenin correlate with cyclin D1 overexpression and poor prognosis in pancreatic cancer. Int. J. Cancer 2001, 197, 194-197. [CrossRef]

44. Li, Y.J.; Wei, Z.M.; Meng, Y.X.; Ji, X.R. $\beta$-catenin up-regulates the expression of cyclinD1, c-myc and MMP-7 in human pancreatic cancer: Relationships with carcinogenesis and metastasis. World J. Gastroenterol. 2005, 11, 2117-2123. [CrossRef]

45. Lowy, A.M.; Fenoglio-Preiser, C.; Kim, O.J.; Kordich, J.; Gomez, A.; Knight, J.; James, L.; Groden, J. Dysregulation of $\beta$-catenin expression correlates with tumor differentiation in pancreatic duct adenocarcinoma. Ann. Surg. Oncol. 2003, 10, 284-290. [CrossRef]

46. Zeng, G.; Germinaro, M.; Micsenyi, A.; Monga, N.K.; Bell, A.; Sood, A.; Malhotra, V.; Sood, N.; Midda, V.; Monga, D.K.; et al. Aberrant Wnt/ $\beta$-catenin signaling in pancreatic adenocarcinoma. Neoplasia 2006, 8, 279-289. [CrossRef]

47. Pascadi Magliano, M.; Biankin, A.V.; Heiser, P.W.; Cano, D.A.; Gutierrez, P.J.A.; Deramaudt, T.; Segara, D.; Dawson, A.C.; Kench, J.G.; Henshall, S.M.; et al. Common activation of canonical Wnt signaling in pancreatic adenocarcinoma. PLoS ONE 2007, 2, 1-9. [CrossRef]

48. Sano, M.; Driscoll, D.R.; DeJesus-Monge, W.E.; Quattrochi, B.; Appleman, V.A.; Ou, J.; Zhu, L.J.; Yoshida, N.; Yamazaki, S.; Takayama, T.; et al. Activation of WNT/ $\beta$-Catenin Signaling Enhances Pancreatic Cancer Development and the Malignant Potential Via Up-regulation of Cyr61. Neoplasia 2016, 18, 785-794. [CrossRef]

49. Yamazaki, K.; Masugi, Y.; Effendi, K.; Tsujikawa, H.; Hiraoka, N.; Kitago, M.; Shinoda, M.; Itano, O.; Tanabe, M.; Kitagawa, Y.; et al. Upregulated SMAD3 promotes epithelial-mesenchymal transition and predicts poor prognosis in pancreatic ductal adenocarcinoma. Lab. Investig. 2014, 94, 683-691. [CrossRef]

50. Piao, J.; Liu, S.; Xu, Y.; Wang, C.; Lin, Z.; Qin, Y.; Liu, S. Ezrin protein overexpression predicts the poor prognosis of pancreatic ductal adenocarcinomas. Exp. Mol. Pathol. 2015, 98, 1-6. [CrossRef] 
51. Chang, Y.-T.; Peng, H.-Y.; Hu, C.-M.; Huang, S.-C.; Tien, S.-C.; Jeng, Y.-M. Pancreatic cancer-derived small extracellular vesical Ezrin regulates macrophage polarization and promotes metastasis. Am. J. Cancer Res. 2020, 10, 12-37. [PubMed]

52. Petrusel, L.; Rusu, I.; Suharoschi, R.; Seicean, A.; Leucuta, D.C.; Seicean, R. Ezrin Intracellular Cytoskeleton Marker is Over Expressed in Pancreatic Ductal Adenocarcinoma: A Prospective Study. Clin. Oncol. 2021, 6, 1777.

53. Meng, Y.; Lu, Z.; Yu, S.; Zhang, Q.; Ma, Y.; Chen, J. Ezrin promotes invasion and metastasis of pancreatic cancer cells. J. Transl. Med. 2010, 8, 1-14. [CrossRef]

54. Stephen, T.L.; Payne, K.K.; Chaurio, R.A.; Allegrezza, M.J.; Zhu, H.; Perez-Sanz, J.; Perales-Puchalt, A.; Nguyen, J.M.; Vara-Ailor, A.E.; Eruslanov, E.B.; et al. SATB1 Expression Governs Epigenetic Repression of PD-1 in Tumor-Reactive T Cells. Immunity 2017, 46, 51-64. [CrossRef]

55. Taiyab, A.; Holms, J.; West-Mays, J.A. $\beta$-Catenin/Smad3 Interaction Regulates Transforming Growth Factor- $\beta$-Induced Epithelial to Mesenchymal Transition in the Lens. Int. J. Mol. Sci. 2019, 20, 2078. [CrossRef]

56. Leiphrakpam, P.D.; Brattain, M.G.; Black, J.D.; Wang, J. TGF and IGF1R signaling activates protein kinase A through differential regulation of ezrin phosphorylation in colon cancer cells. J. Biol. Chem. 2018, 293, 8242-8254. [CrossRef] [PubMed]

57. Han, F.; Liu, W.; Xiao, H.; Dong, Y.; Sun, L.; Mao, C.; Yin, L.; Jiang, X.; Ao, L.; Cui, Z.; et al. High expression of SOX30 is associated with favorable survival in human lung adenocarcinoma. Sci. Rep. 2015, 5, 1-11. [CrossRef] [PubMed]

58. Klimaszewska-Wiśniewska, A.; Neska-Długosz, I.; Buchholz, K.; Durślewicz, J.; Grzanka, D.; Kasperska, A.; Antosik, P.; Zabrzyński, J.; Grzanka, A.; Gagat, M. Prognostic Significance of KIF11 and KIF14 Expression in Pancreatic Adenocarcinoma. Cancers 2021, 13, 3017. [CrossRef] 